\title{
Evaluation of convective cloud microphysics in numerical weather prediction models with dual-wavelength polarimetric radar observations: methods and examples
}

\author{
Gregor Köcher ${ }^{1}$, Tobias Zinner ${ }^{1}$, Christoph Knote ${ }^{1,3}$, Eleni Tetoni $^{2}$, Florian Ewald $^{2}$, and Martin Hagen ${ }^{2}$ \\ ${ }^{1}$ Meteorologisches Institut, Ludwig-Maximilians-Universität, Munich, Germany \\ ${ }^{2}$ Deutsches Zentrum für Luft- und Raumfahrt, Institut für Physik der Atmosphäre, Oberpfaffenhofen, Germany \\ ${ }^{3}$ Medizinische Fakultät, Universität Augsburg, Augsburg, Germany
}

Correspondence: Gregor Köcher (gregor.koecher@physik.uni-muenchen.de)

Received: 27 September 2021 - Discussion started: 18 October 2021

Revised: 18 January 2022 - Accepted: 20 January 2022 - Published: 1 March 2022

\begin{abstract}
The representation of cloud microphysical processes contributes substantially to the uncertainty of numerical weather simulations. In part, this is owed to some fundamental knowledge gaps in the underlying processes due to the difficulty of observing them directly. On the path to closing these gaps, we present a setup for the systematic characterization of differences between numerical weather model and radar observations for convective weather situations. Radar observations are introduced which provide targeted dual-wavelength and polarimetric measurements of convective clouds with the potential to provide more detailed information about hydrometeor shapes and sizes. A convectionpermitting regional weather model setup is established using five different microphysics schemes (double-moment, spectral bin ("Fast Spectral Bin Microphysics", FSBM), and particle property prediction (P3)). Observations are compared to hindcasts which are created with a polarimetric radar forward simulator for all measurement days. A cell-tracking algorithm applied to radar and model data facilitates comparison on a cell object basis. Statistical comparisons of radar observations and numerical weather model runs are presented on a data set of 30 convection days. In general, simulations show too few weak and small-scale convective cells. Contoured frequency by altitude diagrams of radar signatures reveal deviations between the schemes and observations in ice and liquid phase. Apart from the P3 scheme, high reflectivities in the ice phase are simulated too frequently. Dualwavelength signatures demonstrate issues of most schemes to correctly represent ice particle size distributions, produc-
\end{abstract}

ing too large or too dense graupel particles. Comparison of polarimetric radar signatures reveals issues of all schemes except the FSBM to correctly represent rain particle size distributions.

\section{Introduction}

In numerical weather models, clouds play an important role by strongly affecting, e.g., the radiation budget or the precipitation formation. Cloud processes are generally divided into two scales: the macrophysics and the microphysics. We refer to "cloud macrophysics" for processes on a kilometer scale, namely cloud geometry or cloud coverage, while we refer to "cloud microphysics" for all processes on a millimeter scale or smaller. On coarse-grid weather models, both macro- and microphysics are unresolved and must be parameterized. Increasing computational power allows numerical weather models to use finer grid spacings, which in turn allow more and more small-scale processes to be simulated explicitly. Meanwhile, some operational weather models partially resolve convective updrafts (e.g., Pinto et al., 2015; Baldauf et al., 2011; Seity et al., 2011; Lean et al., 2008, and many more). This progress effectively removes problems arising from cloud macrophysical parameterizations, as they can eventually be solved explicitly. However, this is not the case for microphysical processes due to the large number of hydrometeors present in a cloud. Microphysical processes occur on scales of millimeters or smaller and are not 
expected to ever be resolved. As such, the parameterization of microphysics in numerical weather simulations is of increasing relative importance the more the model grid spacing decreases.

Although it is well known that cloud microphysics introduce substantial uncertainty to numerical weather simulations (Li et al., 2009; White et al., 2017; Khain et al., 2015; Xue et al., 2017; Morrison et al., 2020, and many more), the extent of this uncertainty and its underlying reasons remain less clear. Microphysical cloud processes are very complex small-scale processes, due to the large variety of shapes, sizes, and phases of hydrometeors involved. It is a challenge to represent this complexity correctly in a model since it cannot be resolved explicitly. Instead, the effect of the microphysical processes must be parameterized. This has the potential to introduce uncertainties, as important processes could be misrepresented or missed out completely. In numerical weather models, different microphysical schemes of varying complexity exist to parameterize the microphysical processes. Traditionally, microphysics schemes are categorized into so-called bulk and bin schemes. Bulk schemes assume a predefined shape of the particle size distribution of several hydrometeor classes and predict bulk variables, such as the mass mixing ratio for each of the hydrometeor classes. Depending on the predicted number of variables, the scheme is categorized as a one-moment (e.g., Kessler, 1969), twomoment (e.g., Morrison et al., 2009), or even three-moment scheme (e.g., Milbrandt and Yau, 2005). Bin schemes (e.g., Khain et al., 2004) on the other hand do not assume a predefined shape of the particle size distribution but instead use a number of size bins and predict the variables for each of the bins independently. In recent years some alternative schemes have been developed: the predicted particle properties (P3) scheme (Morrison and Milbrandt, 2015) deviates from partitioning ice particles into categories of hydrometeor classes with corresponding properties but instead predicts the properties of ice particles, such as the riming mass mixing ratio. Lagrangian cloud models (LCMs; e.g., Shima et al., 2009) calculate cloud microphysics based on individual particles (super droplet) that represent a family of particles with the same properties, but this type of scheme will not be covered in the present study.

Several studies have analyzed the performance of cloud microphysics schemes by comparing schemes against each other and against observations (Morrison and Pinto, 2006; Gallus and Pfeifer, 2008; Rajeevan et al., 2010; Jankov et al., 2011; Varble et al., 2014; Fan et al., 2015; Li et al., 2015; Fan et al., 2017; Xue et al., 2017; Han et al., 2019, and many more). However, all of them are limited to case studies. There are some studies that directly use polarimetric radar forward operators to evaluate the performance of cloud microphysics schemes. For instance, Jung et al. (2010) and Snyder et al. (2017) each simulate idealized supercell events to test if the cloud microphysics schemes together with a polarimetric radar forward operator are able to reproduce known supercell radar signatures. Ryzhkov et al. (2011) and Putnam et al. (2017) compare simulated polarimetric radar signals with radar observations to evaluate microphysics schemes but focus on one or two convective cases. Given the large variability between convective cases, a large number of individual cases is necessary to test whether one scheme consistently outperforms others in reproducing observations (Flack et al., 2019; Stanford et al., 2019). Few studies have evaluated microphysics schemes on such a statistical basis. Johnson et al. (2015) used a statistical emulation approach to study the uncertainty produced by several model input parameters but focused on a single idealized convective cloud simulation. Stein et al. (2015) evaluated simulated convective storms over 40 non-consecutive days at varying grid spacings but with only one microphysics scheme. Caine et al. (2013) describe an object-based approach to statistically compare convective cells of a convection-permitting model with radar observations, but they use only two simple microphysics schemes, and their statistics are limited to $4.5 \mathrm{~d}$. By comparing two microphysics schemes for different convective events, White et al. (2017) found that the response to cloud droplet number concentrations differs not only between the schemes, but also significantly between different convective cases. All of this emphasizes the need for an evaluation of several microphysics schemes over a larger data set on a statistical basis. In an extensive recent overview paper on the challenges in modeling cloud microphysics, Morrison et al. (2020) argue that a rigorous uncertainty quantification on a statistical basis could also help to pinpoint the underlying microphysical processes that cause these uncertainties.

Multiple studies attribute weather simulation errors to poorly constrained cloud microphysics, especially for ice or mixed-phase clouds (e.g., Varble et al., 2014; Stanford et al., 2017). The uncertainty resulting from microphysical cloud processes is in part a result of some fundamental knowledge gaps: it is not well known which processes are poorly represented in numerical models (Morrison et al., 2020). This is owing to the difficulty of observing these processes directly. To better constrain the parameters, novel observations are needed to provide corresponding information. These observations must provide information about the key microphysical fingerprints, such as particle properties, their location, or ideally conversion rates between hydrometeor classes. Polarimetric radars allow hydrometeor classes and shapes to be retrieved and are hence suitable to provide observations of cloud microphysical processes. Kumjian (2012) demonstrate the impact of precipitation processes on polarimetric radar signals, though he focuses mainly on rain processes such as raindrop evaporation or size sorting. Within the framework of IcePolCKa (Investigation of the initiation of convection and the evolution of precipitation using simulations and polarimetric radar observations at C- and Ka-band), a sub-project of the DFG Priority Programme 2115 PROM (Polarimetric Radar Observations meet Atmospheric Modelling - Fusion of Radar Polarimetry and Numerical Atmospheric Modelling 
Towards an Improved Understanding of Cloud and Precipitation Processes; Trömel et al., 2021), we exploit the synergy of two polarimetric radars at $\mathrm{C}$ - and $\mathrm{Ka}$-band to provide a observational basis for comparison to numerical weather simulations. We evaluate multiple microphysics of different complexity to answer the following question: how much complexity is necessary to reproduce polarimetric radar observations?

The goal of this study is to tackle two different aspects:

1. Provide novel observations of cloud microphysics based on dual-wavelength and polarimetric radar measurements using a combination of operational and researchgrade radars.

2. Evaluate multiple state-of-the-art cloud microphysics schemes for current generation numerical weather prediction models in a common model framework against observations with a large sample size.

Eventually, the evaluation should help to identify microphysical processes with obvious differences between radar measurements and weather simulations. However, it is difficult to extract the influence of the cloud microphysics schemes because of feedbacks between dynamics and microphysics. There are methods that focus on untangling the microphysical impacts from other impacts, e.g., the "piggybacking" method (e.g., Grabowski, 2014). However, operational weather forecast simulations as a whole will always include the feedbacks between microphysics and dynamics as well. Therefore, we decided to use a framework that is applicable to operational weather forecasts and run it over a large number of cases for a statistical comparison, but in this framework we will not be able to perfectly separate the microphysical impacts from possible feedbacks.

We present a setup for the systematic characterization of differences between model simulations with different microphysics schemes and polarimetric radar observations for convective weather situations. This includes the application of a radar forward simulator to the model output and of an automated cell-tracking algorithm to the observations and simulations alike. This allows convective cell characteristics to be objectively compared in simulations and observations. We apply this framework to a data set consisting of $30 \mathrm{~d}$ of radar observation and simulations with five microphysics schemes of varying complexity.

The potential of the generated data set is demonstrated by showing differences in reflectivity between models and observations in convective clouds to identify issues of microphysics schemes to correctly simulate ice and liquid particle size distributions.

The paper is organized as follows. The methods are described in Sect. 2, which includes our radar data (Sect. 2.1), the simulation setup (Sect. 2.2), a description of the microphysical schemes (Sect. 2.3), the radar forward operator used to bring the model output into radar space (Sect. 2.4), the

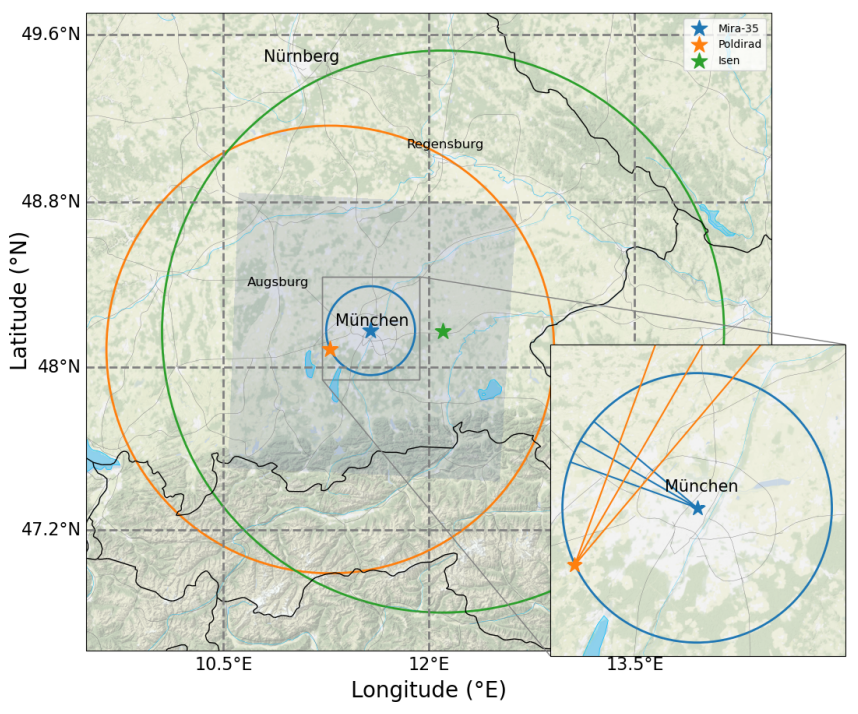

Figure 1. Radar locations and model domain. Filled blue area shows the model domain. Stars show the radar locations and the circles show the radar range around each radar. The straight blue and orange lines visualize RHI scans executed by the Mira-35 and Poldirad radar. Background map tiles by Stamen Design (http: //stamen.com, last access: 16 February 2022), distributed under the Creative Commons Attribution (CC BY 3.0) license. Background map data by OpenStreetMap (http://openstreetmap.org, last access: 16 February 2022; (C) OpenStreetMap contributors YEAR. Distributed under the Open Data Commons Open Database License (ODbL) v1.0.). Roads, rivers, and lakes made with Natural Earth (https://www.naturalearthdata.com, last access: 16 February 2022).

cell-tracking algorithm (Sect. 2.5), and the grid matching of the different radars and the model grid (Sect. 2.6). In Sect. 3 the microphysics schemes are evaluated by comparing statistics of cloud geometry and frequency (Sect. 3.1) as well as analyzing frequency diagrams of reflectivity (Sect. 3.2), polarimetric variables (Sect. 3.3), and dual-wavelength ratio (Sect. 3.4) in simulations and observations. In Sect. 4, the results are discussed.

\section{Data and methodology}

In total, we observed and simulated 30 convective days over 2 years in 2019 and 2020. The majority of these days were in spring and summer. For all of them, convective precipitation was forecasted. A table listing the dates can be found in Appendix A.

\subsection{Radar data}

The observational data basis is provided by two research radar systems in the area of Munich, Germany, at C- and Kaband frequencies, and a complementary second C-band radar operated by the German Weather Service (DWD; Fig. 1). The C-band research radar Poldirad (Schroth et al., 1988), oper- 
ated by the German Aerospace Center (DLR), is located in Oberpfaffenhofen southwest of Munich. At $23 \mathrm{~km}$ distance, the research Ka-band radar Mira-35 is operated by the Meteorological Institute Munich (MIM) of the Ludwig Maximilian University (LMU) in the center of Munich. The third radar is an operational C-band radar located in Isen at a distance of $40 \mathrm{~km}$ to the Mira-35 radar.

All three radars are polarimetric Doppler radars. Poldirad and the Isen radar are fully polarimetric, sending out electromagnetic waves with horizontal and vertical polarization. Both radars receive the co-polar components backscattered by atmospheric targets. Therefore, polarimetric variables such as differential reflectivity $\left(Z_{\mathrm{DR}}\right)$ or specific differential phase $\left(K_{\mathrm{DP}}\right)$ are available. Poldirad additionally receives the cross-polar components and hence measures the linear depolarization ratio (LDR). The Mira-35 radar is a single-polarization ground-based cloud radar manufactured by METEK GmbH (Görsdorf et al., 2015). It only transmits horizontally polarized waves but receives co- and cross-polar components. Thus, it is possible to measure LDR in addition to the standard reflectivity.

Poldirad and Mira-35 are two research radars without any operational obligations. This allows for synchronized and targeted scan patterns of convective clouds and precipitation on demand. The absolute calibration of reflectivity $Z$ of Poldirad is estimated to have an error of $\pm 0.5 \mathrm{~dB}$ from calibration with an external electronic calibration device (Reimann, 2013), while the reflectivity error of Mira-35 is estimated to be $\pm 1.0 \mathrm{~dB}$ (Ewald et al., 2019). We estimate Poldirad $Z_{\mathrm{DR}}$ to have an offset of about $0.15 \mathrm{~dB}$ from measurements in a liquid cloud layer, where $Z_{\mathrm{DR}}$ near 0 is to be expected. This offset is corrected before any of the subsequent analysis is done. The Isen radar is part of the DWD operational radar network with a fixed observation strategy. For a complete description of the measurement strategy, refer to Helmert et al. (2014). More radar characteristics and configurations can be found in Table 1. This setup allows for dual-wavelength and polarimetric measurements of convective clouds and precipitation in the area of Munich.

Two measurement strategies have been applied. For spatial coverage, only data of the operational DWD Isen radar are utilized in scan strategy A. The Isen radar is running operationally a volume plan position indicator (PPI) scan every $5 \mathrm{~min}$ at 11 elevations from 0.5 to $25^{\circ}$ and over the whole azimuth circle of $360^{\circ}$. This provides a good spatial coverage at a high temporal resolution. In Fig. 1, the green circle depicts the area that is covered by this strategy.

In strategy B, Poldirad and Mira-35 are used for coordinated and targeted scan patterns of the same convective cloud. Strategy B starts with a Poldirad overview scan in PPI mode: the elevation angle is kept constant, and the azimuth angle is varied. After manually choosing a convective cell from this overview PPI, both radars start to execute three fast scans towards this convective target cloud in the rangeheight indicator (RHI) scan mode; i.e., the azimuth angle is kept constant, while the elevation angle is varied. The first scan is executed exactly towards the direction that was chosen; one is directed to $2^{\circ}$ azimuth angle to the left; and one is directed to $2^{\circ}$ azimuth to the right. This scan mode is referred to as sector range-height indicator (S-RHI). The nine intersection profiles resulting from these RHIs give an idea about the variation within the cloud and compensate for potential pointing inaccuracies. In Fig. 1, the six straight lines (three orange and three blue) visualize these RHI scans. After each S-RHI scan the azimuth direction is adjusted slightly, according to the projected movement of the cell. This cell movement is projected using two previous Poldirad overview PPI scans by calculating the displacement at which the crosscorrelation between the two PPI images is at maximum. After a few minutes, the S-RHI scans are stopped (manual), and the procedure starts over with another overview PPI scan. This strategy allows for targeted dual-wavelength observations of convective clouds in high vertical resolution over a significant fraction of their lifetime.

In total, we collected data of strategy B over 5 convective days during summer 2019. The strategy A comprises a larger data set. It consists of the same 5 convective days as well as 25 additional convective days during 2019 and 2020.

\subsection{Simulation setup}

The simulations are performed using version 4.2 of the Weather Research and Forecasting Model (WRF; Skamarock et al., 2019). Initial and lateral boundary conditions are provided by reanalysis data at $0.25^{\circ}$ grid spacing from the Global Forecast System (GFS; National Centers for Environmental Prediction/National Weather Service/NOAA/U.S. Department of Commerce, 2015), available every $6 \mathrm{~h}$ and with hourly forecast data in between. Horizontally, the setup includes a parent Europe domain $(3750 \mathrm{~km}$ by $3750 \mathrm{~km})$, a two-way nested Germany domain ( $442 \mathrm{~km}$ by $442 \mathrm{~km})$, and a two-way nested Munich domain ( $144 \mathrm{~km}$ by $144 \mathrm{~km}$ ). The vertical domain extends from the surface to $5 \mathrm{hPa}$ at 40 vertical levels. The nesting ratio is $5: 1$ with the Europe domain at a horizontal grid spacing of $10 \mathrm{~km}$, the Germany domain at $2 \mathrm{~km}$, and the Munich domain at $400 \mathrm{~m}$. Currently, operational limited area weather models operate at $2 \mathrm{~km}$ grid spacing (e.g., $2.8 \mathrm{~km}$ in COSMO-DE of the German Weather Service; Baldauf et al., 2011), which means our inner domain has a resolution that is effectively about 5 times higher and should represent the future of operational limited area weather models most likely including advanced microphysics handling. The Munich domain is centered over the Mira-35 instrument $\left(48.15^{\circ} \mathrm{N}, 11.57^{\circ} \mathrm{E}\right)$. It covers the Mira-35 range $(48 \mathrm{~km})$ and an edge region of an additional $48 \mathrm{~km}$ around. All analyses are performed on the innermost Munich domain excluding the edge region, only considering the Mira-35 range (Fig. 1). This area is completely covered by the Poldirad and Isen radar observations. Each simulation consists of $6 \mathrm{~h}$ spin-up and $24 \mathrm{~h}$ simulation time. The spin- 
Table 1. Radar characteristics. For the Isen radar, the precipitation scan at $1.5^{\circ}$ elevation was referenced. For the full configuration of the volume scan, see Helmert et al. (2014).

\begin{tabular}{llll}
\hline & Poldirad & Mira-35 & Isen \\
\hline City & Oberpfaffenhofen & Munich & Isen \\
Location & $48.087^{\circ} \mathrm{N}, 11.279^{\circ} \mathrm{E}$ & $48.148^{\circ} \mathrm{N}, 11.573^{\circ} \mathrm{E}$ & $48.175^{\circ} \mathrm{N}, 12.102^{\circ} \mathrm{E}$ \\
Wavelength & $5.45 \mathrm{~cm}$ & $0.85 \mathrm{~cm}$ & $5.3 \mathrm{~cm}$ \\
Frequency & $5.5 \mathrm{GHz}$ & $35.2 \mathrm{GHz}$ & $5.66 \mathrm{GHz}$ \\
Beamwidth & $1^{\circ}$ & $0.6^{\circ}$ & $0.9^{\circ}$ \\
Range & $120 \mathrm{~km}$ & $24 \mathrm{~km}$ & $150 \mathrm{~km}$ \\
\hline
\end{tabular}

up always starts at 18:00 UTC (20:00 LST) on the previous day. Thus, the $24 \mathrm{~h}$ forecast exactly covers the day of interest (00:00-24:00 UTC). The dynamics can freely evolve during the simulation time. The parent Europe domain is nudged towards the global GFS data, by appending a nudging term to the prognostic equations for humidity, temperature, and wind that "nudges" the WRF grid value towards the closest GFS grid value for each grid point of the Europe domain above the planetary boundary layer (grid analysis nudging). The inner Germany and Munich domain are not nudged. All days are simulated with five different microphysics schemes. Hence, there are five simulations available for each of the convective days, and the simulation setups only differ in the choice of the microphysics scheme. Other physics options include the Noah land surface model (Ek et al., 2003; Chen and Dudhia, 2001), the MYNN2 planetary boundary layer scheme (Mellor-Yamada scheme by Nakanishi and Niino; Nakanishi and Niino, 2006), and the RRTMG radiation scheme (rapid radiative transfer model for general circulation models; Iacono et al., 2008). For any other options, please refer to the WRF namelist that is provided in the Supplement.

\subsection{Description of microphysics schemes}

Five different microphysics schemes are employed: three three-moment bulk schemes, one from Thompson et al. (2008) (from here on "Thompson"), the one from (Thompson and Eidhammer, 2014) ("Thompson aerosol-aware"), and the one from (Morrison et al., 2009) ("Morrison"), as well as the "Fast Spectral Bin Microphysics" (FSBM; Shpund et al., 2019) and the "predicted particle properties" scheme (P3; Morrison and Milbrandt, 2015). The FSBM scheme explicitly resolves the particle size distribution (PSD) with a number of bins, while all other schemes generally represent the PSD by a gamma function

$N(D)=N_{0} D^{\mu} e^{-\lambda D}$,

where $N_{0}$ is the intercept parameter, $D$ is the particle maximum diameter, $\mu$ is the shape parameter, and $\lambda$ is the slope parameter. The only exception is snow in the Thompson schemes following a bimodal gamma function as described below.
The mass-size relationships are given by a power law,

$m=a D^{b}$,

where $m$ is the particle mass, and $D$ is the particle diameter. The parameters $a$ and $b$ depend on the hydrometeor class and the scheme used and are described below.

a. Thompson. The Thompson bulk scheme predicts integral moments of the PSD for five hydrometeor species: cloud ice, cloud water, rain, snow, and graupel. Rain and cloud ice are double-moment species which predict mass mixing ratio $(q)$ and number concentration $(N)$. Snow, graupel, and cloud water are single-moment; i.e., only the mass mixing ratio is predicted.

The PSDs of rain, cloud ice, graupel, and cloud water are represented by gamma distributions (Eq. 1). For rain, graupel, and cloud ice $\mu=0$; i.e., the PSD is an exponential function. Snow and cloud ice have a fixed non-zero $\mu$.

The mass-size relation follows a power law (Eq. 2). Rain, graupel, cloud ice, and cloud water are assumed to be spherical $(b=3)$, with the parameter $a$ depending on the hydrometeor bulk density $\rho$, with

$a=\rho \frac{\pi}{6}$.

The bulk density of rain, graupel, cloud ice, and cloud water is constant and size-independent.

Snow is treated differently in the Thompson scheme compared to other bulk schemes. Instead of the simple gamma function shown in Eq. (1), a bimodal gamma distribution (sum of an exponential and a gamma function) from Field et al. (2005) that is dependent on temperature is used. Snow is not considered to have a constant density across the particle size distribution; the mass is proportional to $D^{2}(b=2)$ to better fit observations. The parameter $a$ of the mass-size relation is constant at $a=0.069$.

b. Thompson aerosol-aware. The Thompson aerosolaware bulk scheme (Thompson and Eidhammer, 2014) 
is very similar to the older version (Thompson et al., 2008) described in the previous section but includes some changes: while the older version of the Thompson scheme only uses two two-moment species (rain and cloud ice) and a prescribed number of cloud droplets, the newer version includes activation of aerosols as cloud condensation nuclei (CCN) and ice nuclei (IN). Therefore, it explicitly predicts the droplet number concentration of cloud water and two aerosol variables (CCN and IN).

c. Morrison. The Morrison bulk scheme predicts integral moments of the PSD for five hydrometeor species: cloud ice, cloud water, rain, snow, and graupel. All are double-moment species. Particle size distributions follow a general gamma distribution (Eq. 1). Rain, cloud ice, snow, and graupel have shape parameter $\mu=0$, again transforming the particle size distributions into an exponential distribution. For cloud water, $\mu$ is a function of droplet number concentration following Martin et al. (1994). All particles are assumed to be spherical with fixed and size-independent bulk densities.

d. Spectral bin. In contrast to the bulk schemes, a spectral bin scheme explicitly resolves the PSD by approximation with a number of independent size bins. This has the advantage that no prior assumption about the shape of the PSD is necessary. However, computational costs are much higher, as all microphysical processes are computed for each bin separately. In this study we use the Fast Spectral Bin Microphysics scheme (FSBM; Shpund et al., 2019) that applies 33 mass-doubling bins; i.e., the mass of the bin $k$ is twice the mass of the bin $k-1$. Five hydrometeor classes are included: cloud water, cloud ice, rain, graupel, and snow.

e. Predicted particle properties (P3). The $\mathrm{P} 3$ scheme uses three bulk categories: rain, cloud water, and, unlike all the previous schemes, only a single ice category. Instead of predicting mixing ratio and number concentration for multiple ice categories, the $\mathrm{P} 3$ scheme predicts properties of this single ice category. Four prognostic ice mixing ratio variables are predicted: total ice mass, rime mass, rime volume, and number mixing ratio. Based on these variables more properties are derived, such as rime mass fraction $F_{\mathrm{r}}$ (ratio of rime mass and ice mass mixing ratio) or rime density $\rho_{\mathrm{r}}$ (ratio of rime mass and rime volume mixing ratio). All particle size distributions follow a general gamma distribution (Eq. 1). For cloud droplets, the shape parameter $\mu$ follows observations of Martin et al. (1994). For rain, $\mu$ follows observations of Cao et al. (2008). For ice, $\mu$ follows observations of Heymsfield (2003).

Mass-size relationships follow a power law (Eq. 2). The parameters $a$ and $b$ depend on the size of the ice. The scheme distinguishes between small ice, unrimed ice, partially rimed ice, and fully rimed ice (grau$\mathrm{pel} / \mathrm{hail})$. Small ice and graupel are considered spherical $(b=3)$ with parameter $a$ given by Eq. (3), where the ice bulk density $\rho$ equals $917 \mathrm{~kg} \mathrm{~m}^{-3}$ for small ice and varies for graupel/hail. Unrimed ice, grown by vapor diffusion or aggregation, and partially rimed ice have an effective density that is generally less than that of an ice sphere $(b=1.9)$. The parameter $a$ follows an empirical relationship from Brown and Francis (1995) $\left(a=0.0121 \mathrm{~kg} \mathrm{~m}^{-b}\right)$ for unrimed ice and depends on the rime mass fraction $F_{\mathrm{r}}$ for partially rimed ice $\left(a=0.0121 /\left(1-F_{\mathrm{r}}\right) \mathrm{kg} \mathrm{m}^{-\mathrm{b}}\right)$; i.e., $a$ increases with the rime mass fraction. Rain and cloud water are considered spherical with $b=3$ and $a$ following Eq. (3) and a bulk density $\rho$ of $1000 \mathrm{~kg} \mathrm{~m}^{-3}$.

\subsection{Radar forward operator}

To compare the WRF model output against radar observations, version 3.33 of the Cloud-resolving model Radar SIMulator (CR-SIM; Oue et al., 2020) is used. CR-SIM is based on the T-matrix method to compute the scattering characteristics of hydrometeors and is able to simulate polarimetric and Doppler radar variables for several radar frequencies, including C-band and Ka-band that are used in this study. The variables include, among many others, the reflectivity $(Z)$ and specific attenuation $(A)$ at vertical and horizontal polarization, differential reflectivity $\left(Z_{\mathrm{DR}}\right)$, and specific differential attenuation (ADP). Given that CR-SIM supports both $\mathrm{C}$ - and Ka-band frequencies, we are also able to simulate the dual-wavelength ratio (DWR) by performing the forward simulation for the C-band radar as well as the Kaband radar. The dielectric constant of water is 0.92 . Solidphase hydrometeors are assumed to be dielectric dry oblate spheroids and are represented as air in an ice matrix. The refractive index hence depends on the hydrometeor density and is computed using the Maxwell Garnett (1904) mixing formula. There are no mixed-phase particles simulated. This means mixed-phase radar signatures (for example the "bright band"; Austin and Bemis, 1950) will not be reproduced by the simulation. In order to simulate polarimetric radar observables, a radar forward simulator must assume particle shapes and particle orientation. The particle orientation assumptions are the same for all schemes. It is assumed that the particle orientations are 2D Gaussian-distributed with zero mean canting angle as in Ryzhkov et al. (2011). The width of the angle distributions is specified for each hydrometeor class: $10^{\circ}$ for cloud, rain, and ice and $40^{\circ}$ for snow, unrimed ice, partially rimed ice, and graupel. Regarding the shape assumptions, cloud droplets are simulated as spherical (aspect ratio (AR) of 1), and raindrops are simulated as oblate spheroids with a changing axis ratio dependent on the drop size according to Brandes et al. (2002) in all schemes. For ice hydrometeor classes, the same aspect ratio assumptions 
are applied for all schemes except the P3 scheme: cloud ice is assumed as oblate with a fixed aspect ratio of 0.2. Snow is assumed as oblate with a fixed aspect ratio of 0.6. Graupel is assumed to be oblate with an aspect ratio that is changing from 0.8 to 1 , dependent on the diameter and according to Ryzhkov et al. (2011):

$\mathrm{AR}=1.0-0.02$ if $D<10 \mathrm{~mm}$,

$\mathrm{AR}=0.8$ if $D>10 \mathrm{~mm}$.

The P3 scheme does not provide the standard ice hydrometeor classes. Instead, the aspect ratio of small ice (spherical, fixed aspect ratio of 1), unrimed ice (oblate, fixed aspect ratio of 0.6), partially rimed ice (oblate, fixed aspect ratio of 0.6) and graupel (spherical, fixed aspect ratio of 1) is assumed by CR-SIM. This means in comparison to the other schemes that the P3 simulation deviates for small ice (aspect ratio of 1 in $\mathrm{P} 3$, while cloud ice in other schemes is assumed to have an aspect ratio of 0.2$)$ and graupel (0.8-1 in other schemes, while graupel particles in $\mathrm{P} 3$ are assumed to have an aspect ratio of 1). Resulting differences in the radar signal are discussed in the results in Sect. 3 whenever it might influence the simulated radar signal.

\subsection{Cell tracking}

This study focuses on convective clouds and precipitation. To identify and track convective cells in simulations and observations, the open-source Python package TINT (TINT is not TITAN; Fridlind et al., 2019) is used. TINT is based on the Thunderstorm Identification, Tracking, Analysis, and Nowcasting package (TITAN; Dixon and Wiener, 1993). Convective cells are identified using minimum thresholds for reflectivity ( $32 \mathrm{dBZ}$ ) and cell area $\left(8 \mathrm{~km}^{2}\right) ; 32 \mathrm{dBZ}$ is at a common magnitude to identify convective storms (e.g., Dixon and Wiener, 1993; Jung and Lee, 2015). Higher thresholds potentially miss moderate or weaker convective cells, while lower thresholds will misidentify more non-convective echoes as convective cells. A cell motion vector is found by calculating cross-correlation of the reflectivity field in the cell neighborhood of two subsequent time steps and a correction based on prior cell movement. Possible convective cell pairs are compared and matched using an algorithm from TITAN that uses a cost function combining travel distance and volume change of the possible cell pairs. The cell tracking is applied to simulated and observed reflectivity of the Isen radar only. The simulated and observed reflectivity from Mira-35 and Poldirad is not used for cell tracking. This way we ensure that we have one unique definition to locate convective cells and prevent varying cell definitions depending on the radar that is simulated. More detailed information about TINT can be found in Fridlind et al. (2019) and Dixon and Wiener (1993). TINT does not deal with splits (one cell splits into multiple cells) or mergers (multiple cells merge into one cell), but it was specifically designed for the tracking of convective cells

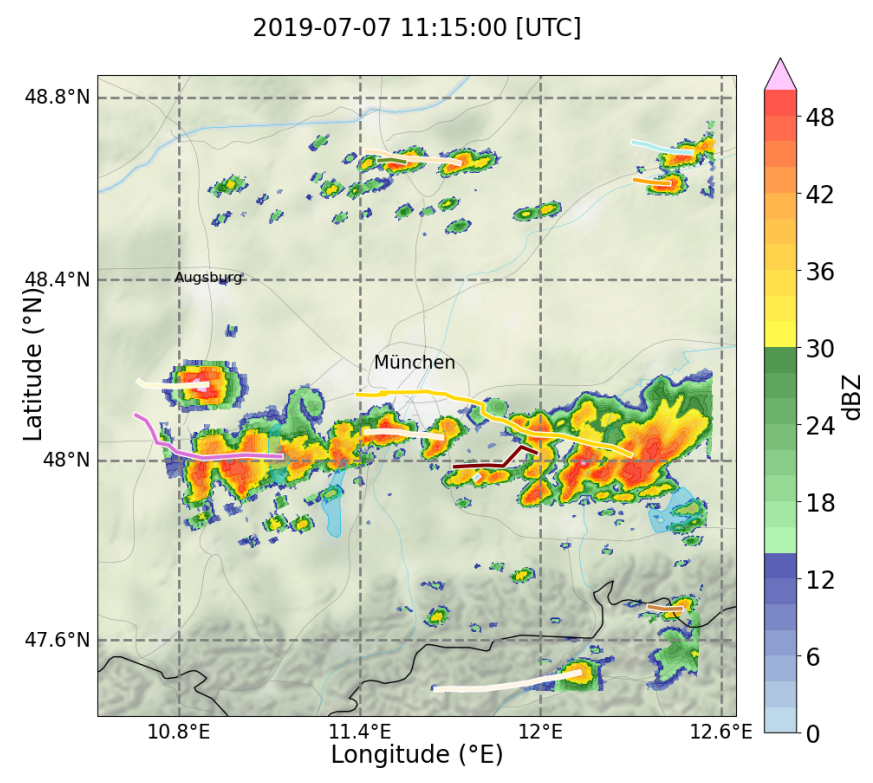

Figure 2. Example of cell tracking with TINT: colored background is the reflectivity simulated with WRF and CR-SIM, and solid lines and numbers represent the TINT tracks and TINT cell identifier.

over large data sets and is straightforward to apply to our data (Fig. 2).

\subsection{Grid matching and attenuation correction}

Radar data and model output are available on different grids. To allow for a comparison, these grids must be matched first. In a first step, the model data are transformed to a spherical grid of the corresponding radar. For example, simulated Mira-35 radar data are transformed to a spherical grid with a range resolution of about $31 \mathrm{~m}$ and a maximum range of $24 \mathrm{~km}$. The transformation utilizes the source code radar_filter, which is available on the website of Stony Brook University, together with the CR-SIM source code (https: //you.stonybrook.edu/radar/research/radar-simulators/). The radar_filter considers beam propagation effects; i.e., for the interpolation to a grid point of the target spherical grid, all Cartesian input grid points that are within the beam width are included with a weight depending on the distance to the radar volume center. If no Cartesian grid point falls into the radar beam, the nearest grid point is used. In the next step, attenuation correction is applied along the beam. The correction is applied by subtracting the accumulated (along the range coordinate) simulated attenuation from the uncorrected reflectivity

$Z_{\mathrm{corr}, \mathrm{r}}=Z_{\mathrm{r}}-2 \cdot \Delta r \cdot \sum_{i=0}^{i=r} A_{\mathrm{i}}$.

Here the simulated reflectivity without attenuation correction at range gate $r$ is given by $Z_{\mathrm{r}} . A_{\mathrm{i}}$ is the simulated attenuation in decibels per meter at range gate $i$, and $\Delta r$ is the 
radar range resolution in meters. The factor 2 takes into account the fact that the beam travels twice through each grid box (from antenna to target and back). In the same way, the differential reflectivity $Z_{\mathrm{DR}}$ is corrected with the simulated differential attenuation ADP.

In a last step, all data (model and radar) are transformed back to a Cartesian grid that exactly covers the Munich domain of the model $(144 \mathrm{~km}$ by $144 \mathrm{~km})$ with a $400 \mathrm{~m}$ by $400 \mathrm{~m}$ by $100 \mathrm{~m}$ (vertical) grid spacing. This is done by applying a nearest neighbor interpolation that chooses the closest radar bin for each of the Cartesian grid points. Only grid boxes within the lowest and highest radar beam are considered. All grid boxes below the lowest or above the highest beam are masked out. Then, the cell tracking with TINT is applied to this Cartesian grid in exactly the same way for model and radar data, by passing Py-ART grid objects (Helmus and Collis, 2016) created from the Cartesian grid data to TINT.

\section{Comparison of model and radar observations}

An example for the impact of the microphysics scheme choice is given in Fig. 3. It shows the total accumulated precipitation over the Munich area as simulated by WRF simulations while only varying the microphysics scheme. Overall, the total accumulated precipitation over the whole domain and over longer periods (Fig. 3a; 30 d) is similar between all schemes except the bin scheme. However, the deviations can be much larger during single days (e.g., Fig. 3b; 1 August 2020). The total precipitation over all surface grids varies between all five schemes, in this case by more than $6 \times 10^{7} \mathrm{~m}^{3}$ between the P3 and the bin scheme. This illustrates the variation between simulations as a result of the choice of microphysics scheme alone. In the following part, we analyze the resulting deviations in more detail.

\subsection{Cloud geometry and frequency}

We begin our comparison with an evaluation of the geometric properties of simulated and observed clouds. Figure 4 shows histograms of the convective cell core extent (altitude of continuous $32 \mathrm{dBZ}$ volumes) as well as the maximum cell reflectivity provided by strategy A. At each 5 min time step during 30 convective weather days, all cell detections are summed up on DWD Isen observation data or CR-SIM forward simulations. This means that this analysis is independent of possible matching errors of the cell tracking, as the identified convective cells at each time step are counted independently; e.g., a single cell detected for 30 min would contribute to the statistics six times. The cell core top heights of observed cells (Fig. 4a) show a distinct peak with more than 2000 cell detections at an altitude of 3-4 km. This corresponds to about $40 \%$ of all cell detections by the radar. All numerical weather prediction (NWP) simulations inde- pendent of the microphysics scheme are able to reproduce a peak at a similar altitude but none of them as pronounced as in the observations. The two Thompson schemes show a tendency towards slightly higher cell core heights of $4-5 \mathrm{~km}$. Reflectivities of more than $32 \mathrm{dBZ}$ above the melting layer are mostly related to big graupel particles in our simulations and, to a lesser extent, rain likely lifted by updrafts. In particular, the Thompson schemes more frequently simulate graupel particles that produce very high reflectivities of more than $45 \mathrm{dBZ}$ above the melting layer (see Appendix B).

A similar approach to compare cloud geometry in simulation and radar observation was followed in Caine et al. (2013). They objectively compare simulated cell characteristics with observations over $4.5 \mathrm{~d}$ after applying a celltracking algorithm on their data. Among other things, they found the simulated convective cells to reach higher altitudes on average compared to their radar observations, which is also visible in our analysis. This is independent of the chosen cloud microphysics scheme and mainly a result of the missing small-scale cells in the simulations, which is indicative of a resolution effect: the very small cell heights correspond to small cells that we might not be able to resolve, even with our $400 \mathrm{~m}$ grid spacing.

Regarding the total number of cell detections, the Thompson schemes are closest to the observed number. A total of 5458 cell detections are counted, i.e., the number of cells in all $5 \mathrm{~min}$ observation time steps. The Thompson aerosolaware scheme (6035) is still close to the observed number; the basic Thompson scheme (5468) is the closest; and the P3 (4758) has fewer cells. Especially the Morrison (3427) and FSBM scheme (3326) produce too few convective cells. This difference is mainly a result of missing small-scale development (early stages, weak cells) in the simulations. For fully developed thunderstorms (cell core top heights $>7 \mathrm{~km}$ ), all schemes produce numbers that are slightly larger than in the observations (observations: 554, Thompson: 1139, Thompson aerosol-aware: 948, Morrison: 928, FSBM: 899, P3: 780). The related distribution of maximum reflectivity of each cell provides some clarification (Fig. 4b). The observed high occurrence of weaker cells is only partially visible in FSBM and Morrison schemes. While the total number of weaker cells (max cell reflectivity at $35-40 \mathrm{dBZ}$ ) is still too low, the Morrison and FSBM schemes show the highest relative occurrences for relatively weak cells between 40 $45 \mathrm{dBZ}$ maximum reflectivity. This still does not represent the pronounced peak of observed cells at weaker reflectivities of 35-40 dBZ well. The other three schemes produce too many medium-intensity cells and too few low-intensity cells. At the other end of the reflectivity spectrum, none of the models is able to reproduce the occurrence of the strongest reflectivities at more than $57 \mathrm{dBZ}$. In part, this is most likely related to numerical smoothing of local and rare values in the NWP model. 


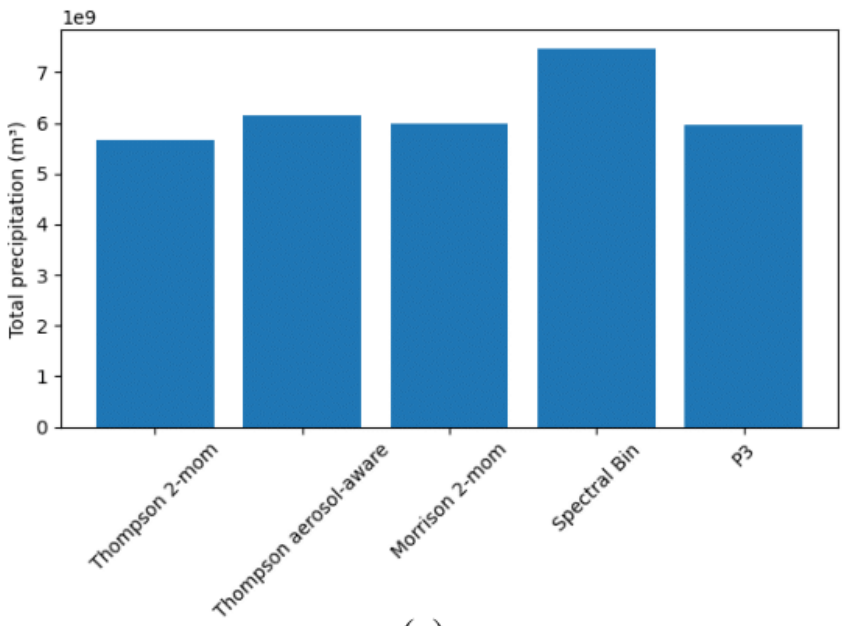

(a)

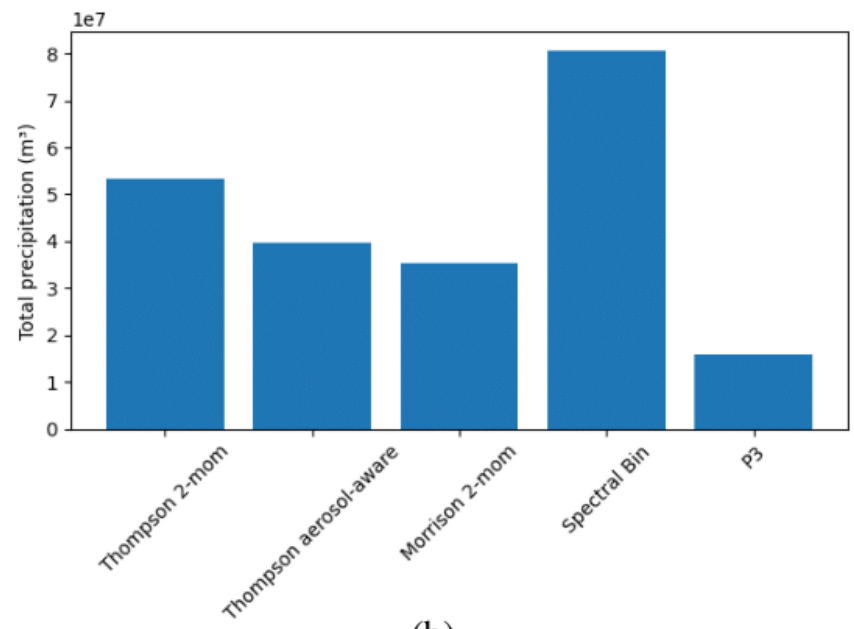

(b)

Figure 3. Total simulated precipitation over (a) $30 \mathrm{~d}$ and (b) on 1 August 2020 over the Munich area.

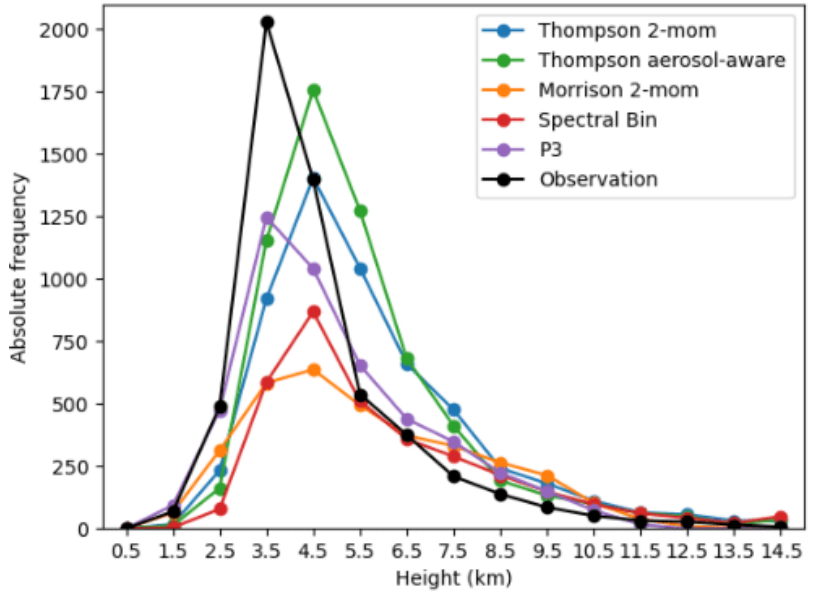

(a)

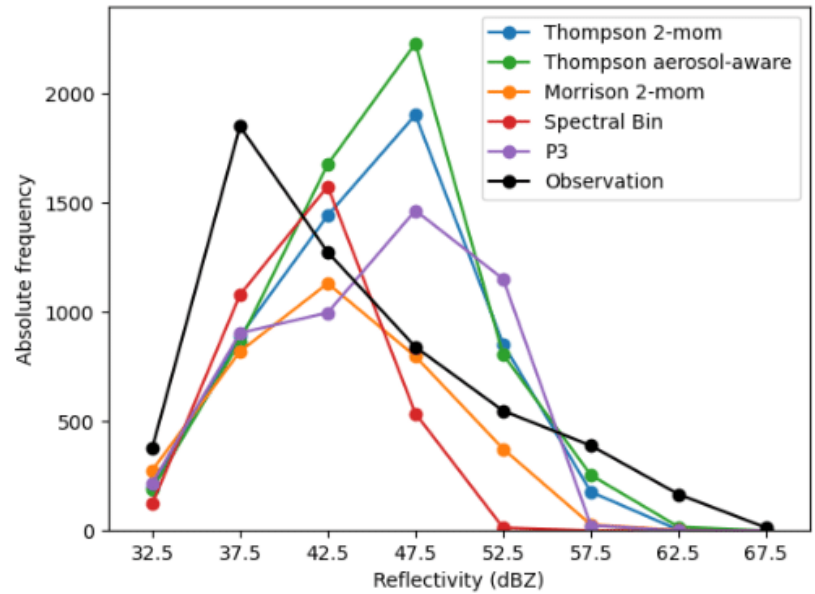

(b)

Figure 4. Cell core height (a) and cell maximum reflectivity (b) distribution for inner simulation domain over 30 convection days for observations and five microphysics scheme simulations.

\subsection{Profiles of reflectivity}

Contoured frequency by altitude diagrams (CFADs; Yuter and Houze, 1995) for reflectivity of observed and simulated convective cells are shown in Fig. 5 provided by scan strategy B. This scan strategy provides dual-frequency profiles of high vertical resolution through convective clouds. The radar observation CFADs contain about 1300 profiles in convective clouds. The simulated CFADs consist of many more profiles (on the order of $10^{5}$ ) because (1) all cells present during one time step on the model domain are analyzed, and (2) all columns within each identified cell are included (as opposed to the $3 \times 3$ profiles that an S-RHI observation provides). The restriction to the center profile of the convective cell, which is a default output of the TINT cell tracking, would have been an alternative approach. We decided against it for three reasons: (1) the observation was targeted at the location of highest reflectivity and the geometric TINT cell center is not necessarily the location of highest reflectivity; (2) using the S-RHI strategy we include more variation from each cell compared to one center profile; and (3) more profiles provide a better statistical basis for intercomparison of schemes. In Fig. 5 the simulated reflectivities are corrected for attenuation to make them comparable to the radar observations. Below the melting layer, high reflectivities of more than 30 and up to $45 \mathrm{dBZ}$ are simulated most frequently. Overall, the schemes agree in the simulated reflectivity in this area, mostly caused by rain and graupel. They differ only in the spread. The Morrison scheme shows a higher spread, more often simulating reflectivities below $30 \mathrm{dBZ}$ and even down to $0 \mathrm{dBZ}$. In con- 


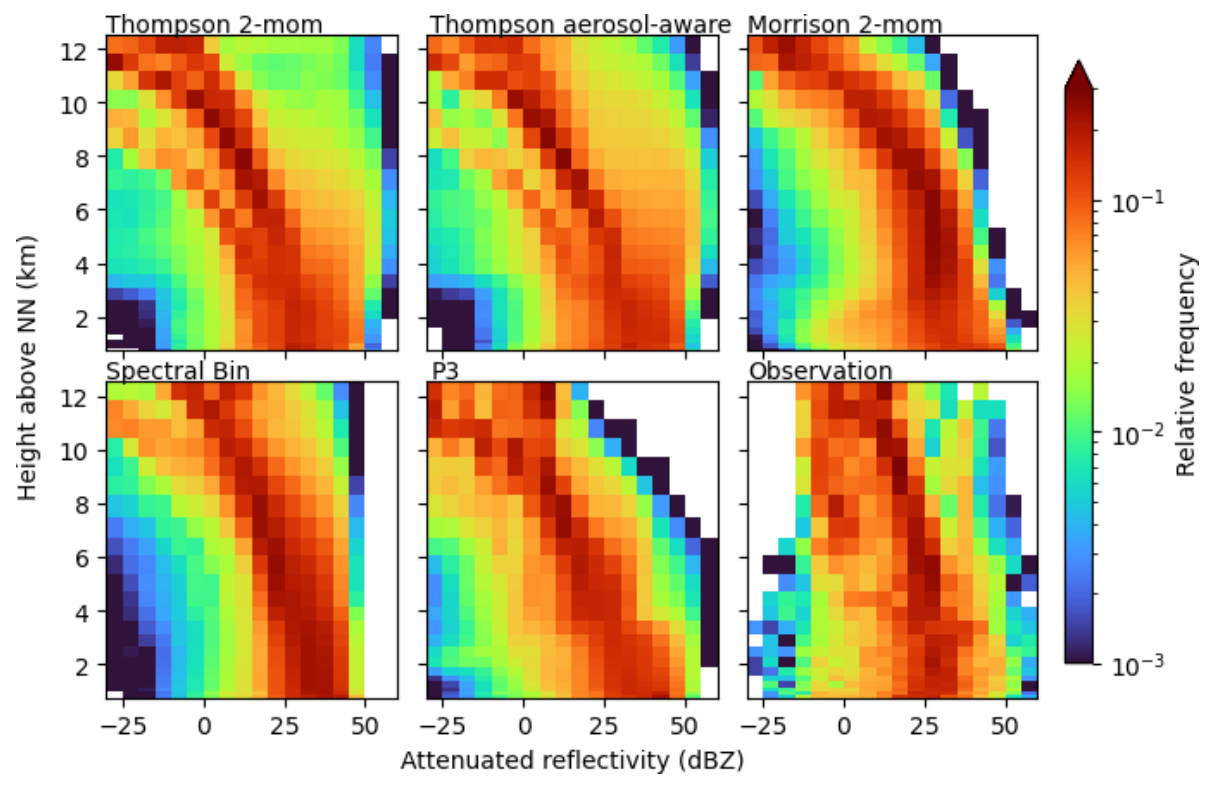

Figure 5. CFADs of simulated and measured reflectivity over 5 convective days in 2019. Radar observations with Poldirad.

trast, the FSBM produces reflectivities below $25 \mathrm{dBZ}$ less often than the others within the convective cells. Compared to the observed CFAD, high reflectivities below the melting layer are generally modeled too frequently. This is in agreement with Putnam et al. (2017), who compare radar signals simulated by five different microphysics schemes for two case studies and find that especially the Morrison scheme, but to a lesser extent also the Thompson scheme, produces $Z$ values that are too high. They attribute this to stratiform rain PSDs that contain too many large drops, to an over-forecast of the precipitation coverage overall, and, in the case of Morrison, to a high bias of wet graupel in convective regions. Given that the forward simulator applied in this study does not consider wet particles, we find the high bias in $Z$ exists even without considering wet graupel and comes mostly from rain, suggesting PSDs that contain too many large raindrops compared to the observations.

Above the melting layer, simulated reflectivities start to decrease with height. This is a fingerprint of ice growth processes where falling particles increase in size by deposition, aggregation, or riming. At these subfreezing heights, the schemes show more deviations from each other. While most schemes exhibit a smooth transition from ice to liquid phase, the prominent exception is the $\mathrm{P} 3$ scheme for which reflectivities abruptly increase by about $15 \mathrm{dBZ}$ at the melting layer height (approximately at $3.6 \mathrm{~km}$ height, varies among cases). All other schemes show a slow and smooth increase in reflectivity, which better agrees with our observations. However, given that the reflectivity within rain was too high, the reflectivity distribution above the melting layer height is reproduced quite well by the P3 scheme. Most other schemes directly above the melting layer height extend to higher re- flectivities, showing reflectivities greater than $25 \mathrm{dBZ}$ too often. The Thompson schemes even simulate reflectivities of more than $45 \mathrm{dBZ}$ above the melting layer height frequently. These extreme reflectivity values are produced mostly by graupel and to a lesser extent by rain (see Appendix B for CFADs of radar signals separated by hydrometeor classes). Compared to our measurements these reflectivities are unrealistically large. A high bias in reflectivity could be produced in principle by three mechanisms: the simulated particles are (1) too dense, (2) too many, or (3) too large. The graupel densities assumed by the schemes (and correspondingly in the forward simulator) are $500 \mathrm{~kg} \mathrm{~m}^{-3}$ in the Thompson schemes and $400 \mathrm{~kg} \mathrm{~m}^{-3}$ in the Morrison and FSBM scheme. The higher graupel density could explain the higher bias seen in the Thompson scheme compared to the moderate bias in Morrison and FSBM, but the underlying PSD could also play a role. Reflectivity overestimation in deep convection at subfreezing temperatures was found by other studies as well (e.g., Stanford et al., 2017; Varble et al., 2011) and is explained to be a result of graupel or snow particles that are too large, likely a product of overly strong updrafts. Stanford et al. (2017) show that this bias not only exists for bulk schemes, but also for a bin scheme. We can confirm that with our simulations, the bias exists for the FSBM scheme too, even though it appears to be strongest in the Thompson scheme. However, this could be a consequence of the higher assumed graupel density.

\subsection{Profiles of polarimetric variables}

The same analysis is possible for simulated and observed polarimetric variables, e.g., differential reflectivity $Z_{\mathrm{DR}}$ (Fig. 6). We found $K_{\mathrm{DP}}$ to provide not much additional value, 


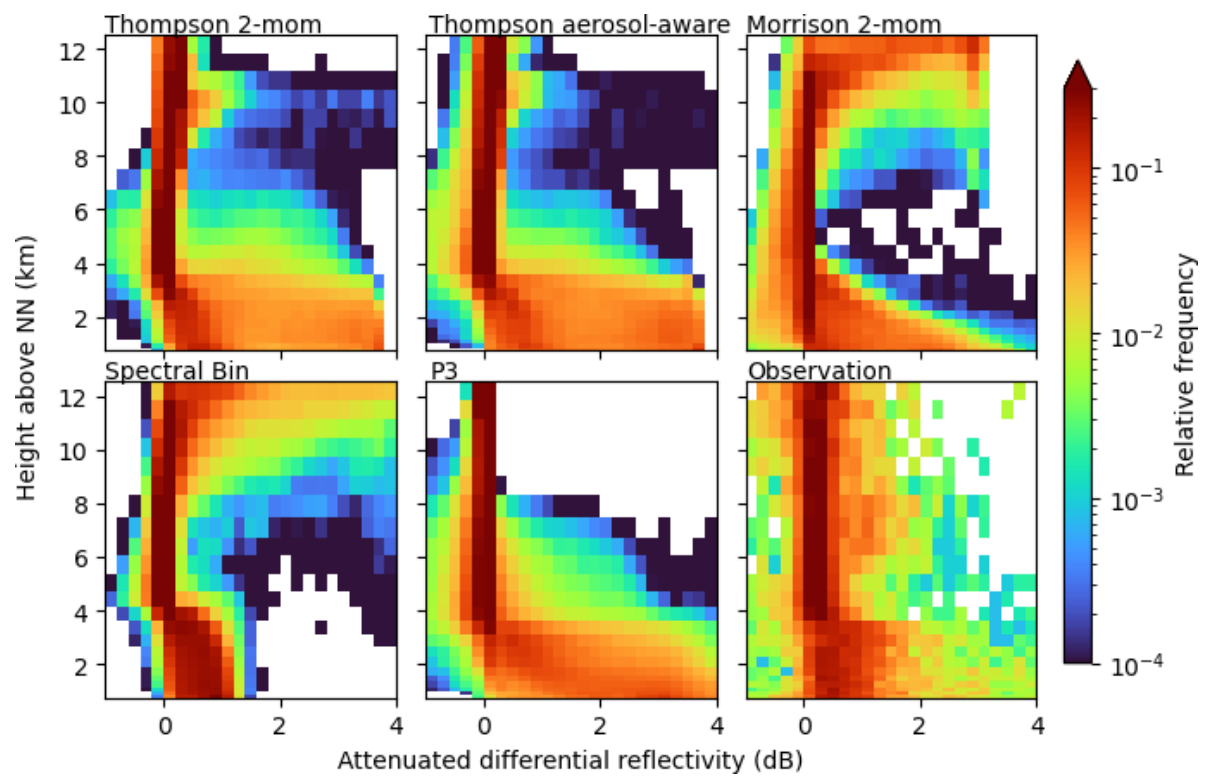

Figure 6. CFADs of simulated and measured differential reflectivity $Z_{\mathrm{DR}}$ over 5 convective days in 2019. Observation with the Poldirad radar.

in part due to noisy observations, which is why we neglect $K_{\mathrm{DP}}$ in the subsequent analysis. Strong differences between the simulations are visible in the liquid phase below the melting layer. While most schemes show a wide spread over the whole range of $0-4 \mathrm{~dB}$ within rain, the FSBM only produces $Z_{\mathrm{DR}}$ values up to around $1.5 \mathrm{~dB}$. This is in much better agreement with the observations, where $Z_{\mathrm{DR}}$ values of up to 1.5 have been measured most of the time, though also covering slightly higher $Z_{\mathrm{DR}}$. Here, the advantage of the FSBM that uses a discrete PSD becomes apparent. The FSBM model is able to explicitly predict rain droplets of each bin, which is more flexible and potentially better captures the variability in observed PSDs (better size-sorting). Ryzhkov et al. (2011), for example, evaluate radar signals simulated from a spectral bin scheme for a hailstorm case and find that their spectral bin scheme produces PSDs for rain that deviate from the gamma distribution. Bulk schemes would not be able to reproduce these PSDs, and since radar signals strongly depend on the PSD, Ryzhkov et al. (2011) argue that spectral bin schemes are better suited to simulate polarimetric radar signals. However, contributions by other microphysical processes, such as drop breakup or evaporation, could also facilitate the $Z_{\mathrm{DR}}$ signatures and were not examined in this study. All other schemes use a gamma distribution (Eq. 1) with a shape parameter $\mu=0$ for rain. This effectively is an exponential (Marshall-Palmer) PSD, which has a slope that is too weak: there are too few small rain droplets and too many big droplets. Putnam et al. (2017) find similar results regarding $Z_{\mathrm{DR}}$ signatures near the surface: in their two case studies, the simulations with Thompson and with Morrison cloud microphysics showed incorrect $Z_{\mathrm{DR}}$ maxima, associated with isolated large drops at locations of weak convection, where this would not be expected. All of this suggests that the underlying rain particle size distributions are better captured by the FSBM compared to the bulk schemes.

In order to separate the analysis into reasons due to differences in the underlying modeled microphysics and due to different processing in the forward simulator, we examined rain particle size distributions directly produced by the NWP model (rain PSD CFAD in Appendix B). The FSBM scheme provides the drop size distributions over a number of size bins; for the bulk schemes we calculated the distributions according to the schemes parameterization. The FSBM bins are approximated by calculating the number of droplets for the geometric center of the FSBM bin. The calculated number of droplets for the given bin center diameters is then summed over all time steps and over the grid boxes at each height and visualized as a relative frequency. Only grid boxes that were flagged as a convective cell by the TINT cell tracking are considered. The rain PSD CFAD confirms the findings of the $Z_{\mathrm{DR}}$ CFAD: the two Thompson schemes simulate large raindrops from the surface up to the melting layer height and even above, while the Morrison scheme produces large raindrops only at the surface, and the FSBM produces the highest frequency of small drops.

Directly above the melting layer, the FSBM and Morrison schemes show $Z_{\mathrm{DR}}$ values close to 0 , while the P3 and the Thompson schemes have their frequency maximum at 0 but also show more spread to higher $Z_{\mathrm{DR}}$ values. A $Z_{\mathrm{DR}}$ of 0 is associated with spherical particles. The signal directly above the melting layer height is generally dominated by graupel, which has the highest reflectivity signal (see Appendix $\mathrm{B}$ for separation by hydrometeor class) and is associated with $Z_{\mathrm{DR}}$ values of 0 , due to the assumed aspect ratio 
of 1 in the forward simulation. The sparse but large values of $Z_{\mathrm{DR}}$ in the two Thompson schemes and the $\mathrm{P} 3$ scheme are predominantly caused by rain, likely lifted by strong updrafts in the convective situations. The FSBM scheme also shows $Z_{\mathrm{DR}}$ signals originating from rain particles in that area, but the total $Z_{\mathrm{DR}}$ is reduced by a significant contribution from other hydrometeors with a lower $Z_{\mathrm{DR}}$. Only the Morrison scheme shows no contribution by lifted raindrops directly above the melting layer. The observations show a little more spread compared to Morrison and FSBM in that area, but the $Z_{\mathrm{DR}}$ does not reach values as high as for the Thompson and P3 schemes. There are multiple possible explanations for the differences to the observations: compared to the observed convective cells, (1) more (fewer) large raindrops are lifted above the melting layer height in Thompson and P3 (Morrison and FSBM); (2) there are more (fewer) particles with spherical nature alongside lifted raindrops in the observations that reduce the total $Z_{\mathrm{DR}}$ compared to Thompson and P3 (Morrison and FSBM). Furthermore, (3) the observed variability of $Z_{\mathrm{DR}}$ is possibly not correctly captured by the radar forward simulator, which has to assume fixed distributions of particle orientations as well as a fixed aspect ratio of the particles.

At upper levels clear differences between Morrison and FSBM and Thompson and P3 can be seen. Morrison and the FSBM scheme show $Z_{\mathrm{DR}}$ values of up to $4 \mathrm{~dB}$ at these heights, while the Thompson schemes and the P3 scheme are close to $0 \mathrm{~dB}$. Here, the high $Z_{\mathrm{DR}}$ values are caused by cloud ice (see Appendix B for CFADs of radar signals separated by hydrometeor class). All schemes assuming spherical cloud ice or with other dominating spherical hydrometeor classes at these heights show small $Z_{\mathrm{DR}}$. This is true for the P3 small ice fraction for which the forward simulator assumes spherical aspect ratio of 1 . In the Thompson schemes, the assumed aspect ratio by the forward simulator is 0.2 , suggesting that other hydrometeor classes with lower $Z_{\mathrm{DR}}$ like snow or graupel dominate the signal. Only for FSBM and Morrison (aspect ratio 0.2) does cloud ice dominate the signal. The stronger signal in FSBM and Morrison is not a result of different density assumptions because both the FSBM and Morrison scheme assume lower density of cloud ice compared to Thompson. The observations do not show increased $Z_{\mathrm{DR}}$ at these heights. This could either mean (1) that there are no large cloud ice particles observed, (2) that the signal is dominated by other more spherical particles in the observations, or (3) that the assumed aspect ratio of 0.2 by the radar forward operator is unrealistic, and the observed particles are more spherical in nature.

\subsection{Profiles of dual-wavelength variables}

More insight about the particle size is provided by the simulated and observed dual-wavelength ratio DWR. The standard radar reflectivity is strongly influenced by the number of particles within the radar beam, the particle sizes, and the particle densities. In contrast, DWR is rather sensitive to the particle size. In principle, it is also sensitive to the particle density, but the simulated density is assumed to be constant or a function of particle size. Figure 7 shows deviations between the schemes within the ice phase as well as in the liquid phase. Here, no attenuation correction is applied. This makes the comparison to the radar observations less realistic but reveals differences in microphysical processes and fingerprints between the simulations more clearly. The observations show DWR close to 0 at upper levels, where ice crystals are very small. All simulations and the observations agree at these heights. The observations then show a steady increase of DWR towards the melting layer height. This is reflecting ice particle growth, given that DWR is mainly sensitive to particle size. All simulations reproduce this increase of DWR towards the melting layer heights but differ in the slope and height where the increase starts. While the Morrison and FSBM simulations already show the beginning of an increase in DWR at about $10 \mathrm{~km}$, the P3 and the two Thompson simulations show the beginning of an increase at about $7 \mathrm{~km}$, which agrees better with the observations. At melting layer heights, the DWR values reach their maximum in all simulations. The magnitude of the maximum DWR values differs: Morrison and FSBM do not produce DWR values larger than $20 \mathrm{~dB}$, while the P3 and the two Thompson schemes produce DWR values of up to $25 \mathrm{~dB}$. At these heights, the two Thompson schemes produce distinct streaks of higher frequencies at low DWR values $(0-10 \mathrm{~dB})$ and then a diffuse area of lower frequencies at higher DWR $(>10 \mathrm{~dB})$. The streaks are related to snow growth during sedimentation. Thompson only uses one mass-size relation for snow, while the P3 is more flexible: it uses a varying mass-size relation depending on whether the ice particle is unrimed, partially rimed, or fully rimed. This is the reason why the DWR corridor in P3 above the melting layer height is wider.

Below the melting layer, the observed DWR steadily decreases towards the ground. The models do not reproduce this very well: even though the DWR decreases in all models, this decrease happens abruptly at the melting layer. The DWR directly below the melting layer height is very different between the models and the observations. However, including attenuation increases the simulated DWR and its variability, making it difficult to quantify DWR deviations between models and observations as discussed below. Below the melting layer height, the simulated DWR stays more or less constant, while the observed DWR decreases towards the surface. In the P3 simulations (and weaker in the Morrison scheme), the DWR even increases again towards the ground. At these heights, rain and graupel are the dominant species. The simulated increase of DWR towards the ground is likely a result of the simulated collection process: rain droplets grow while falling by collecting smaller droplets. This is visible also directly in the rain PSD (see Appendix B) and was discussed in Sect. 3.3. Conversely, the large particles precipitating from the melting layer seem to shrink to- 

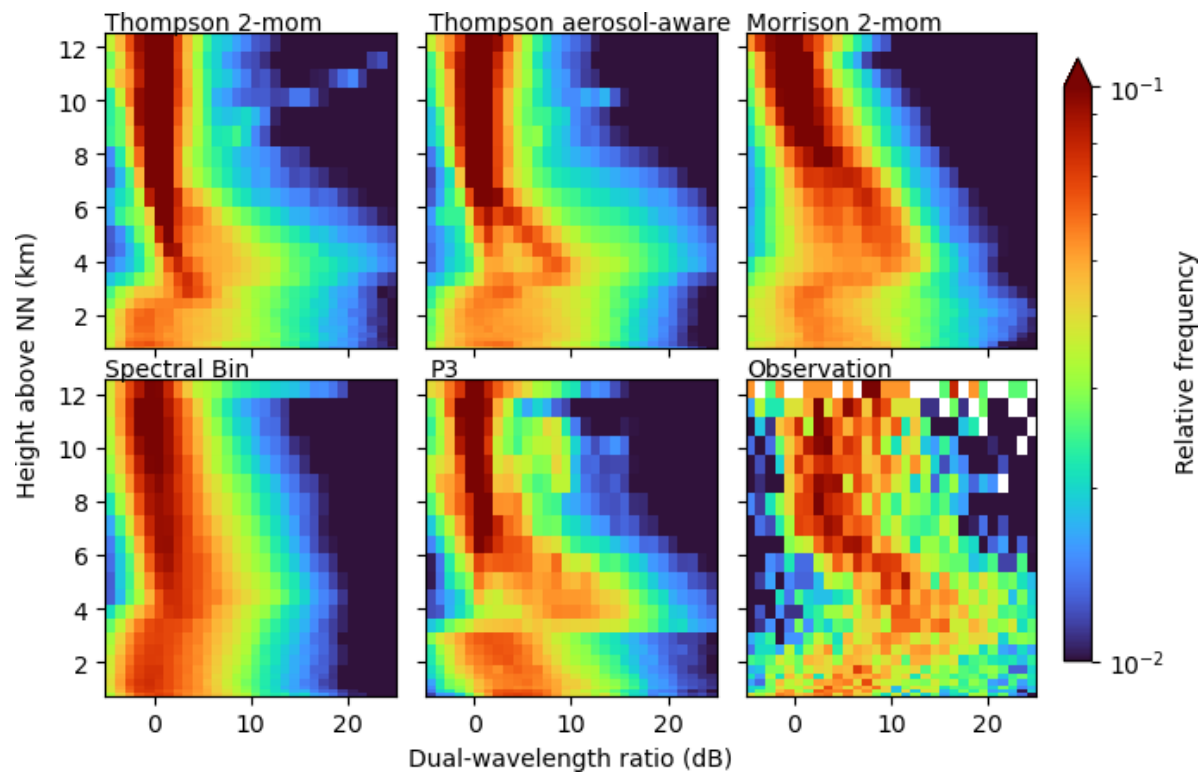

Figure 7. CFADs of simulated and measured DWR over 5 convective days in 2019. Radar observations with Poldirad and Mira35.

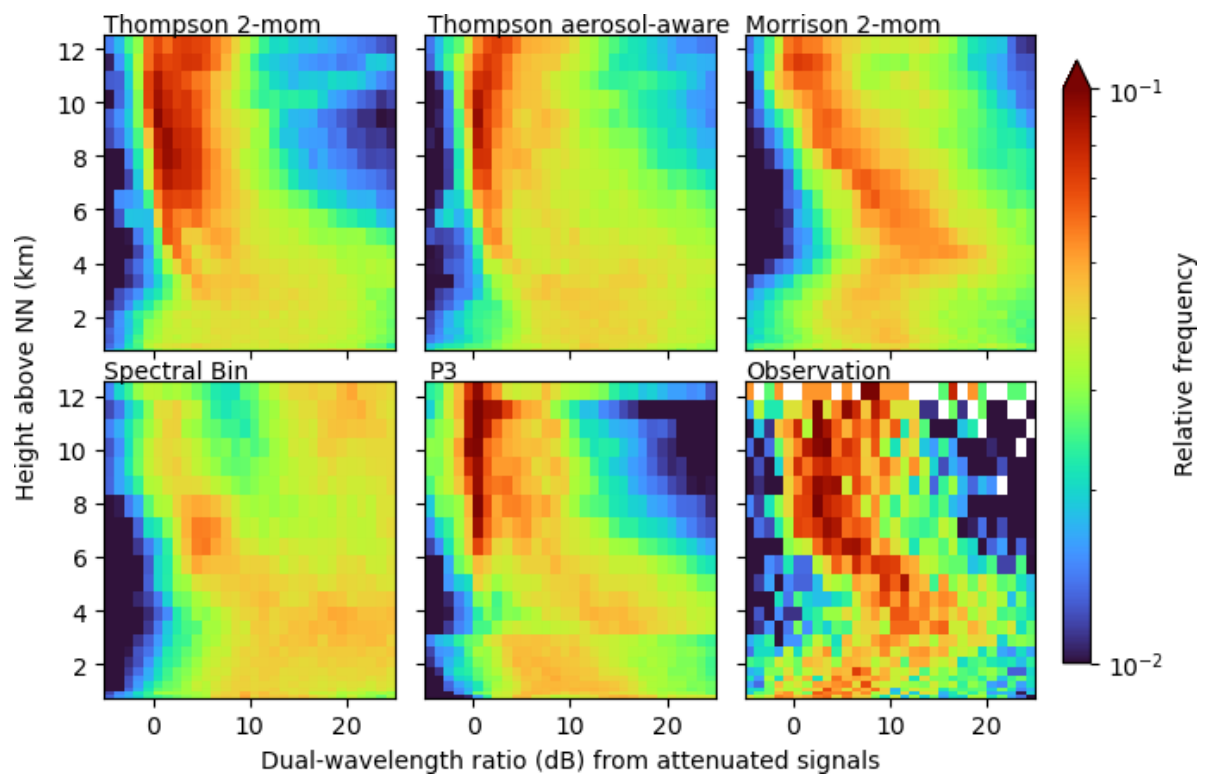

Figure 8. Same as Fig. 7 but with simulated attenuation included in the simulations.

wards the ground, perhaps by drop breakup or evaporation. The general magnitude of simulated DWR values near the surface is close to the observed again at around -3 to $10 \mathrm{~dB}$.

Comparing DWR signatures without including attenuation gives insight into the details of the microphysical schemes but is not well suited for a direct comparison with radar observations because especially the Ka-band observations are potentially strongly attenuated. This would lead to an increase in DWR. Figure 8 shows the same DWR CFADs including attenuation. Obviously, attenuation drastically increases the variability in DWR. As a result, DWR values are scattered over larger ranges, partially masking the underlying fingerprints that were visible in the CFADs without attenuation. Furthermore, the lower number of observed profiles compared to the simulated profiles is still clearly visible. This is most prominent in the DWR CFAD but also in the CFADs of reflectivity (Fig. 5) and $Z_{\mathrm{DR}}$ (Fig. 6). This is reminiscent of the large observational effort to collect targeted cell core RHI scans. 


\section{Summary and conclusions}

A methodological framework has been presented that allows for a statistical comparison of polarimetric dual-wavelength radar observations with numerical weather model output. Targeted dual-radar observations of convective cell characteristics in the vicinity of Munich over a significant fraction of cell lifetime have been established. For the weather model, cell-specific observations of a Ka-band and two Cband radars are produced using a polarimetric radar forward operator and automatic cell tracking. The total data set presented includes 30 convective days of simulation and radar observations so far. Targeted dual-wavelength observations were performed on 5 of those days, adding up to about 1300 RHI profiles of dual-wavelength observations of convective clouds. A convection-permitting WRF setup over Munich has been implemented. WRF hindcast simulations were conducted with five different microphysics schemes of varying complexity. The radar forward simulator CR-SIM was applied that provides polarimetric radar variables from model output. The cell-tracking algorithm TINT was applied on radar and model data in the same way to allow for comparison of convective cell characteristics.

With the exception of the Thompson schemes, all microphysics schemes simulate too few convective cells compared to the radar observations. The difference is mainly caused by missing weak cells with cell core heights between $3-4 \mathrm{~km}$. This points to missing small-scale development in most of the simulations. This suggests dynamical reasons or numerical resolution issues rather than the impact of microphysics schemes. It is a reminder that the presented methodology is not able to perfectly separate microphysics from dynamical feedbacks or other impacts. Statistics of observed and simulated cell reflectivities show that models are not able to reproduce the observed high occurrences of very weak cells, as well as the occurrence of strongest reflectivities at more than $57 \mathrm{dBZ}$. This might be related to numerical smoothing of local and rare values in the NWP model.

Targeted scans of convective clouds revealed differences in radar observations and models as well as between microphysics schemes in ice and liquid phases. Overall, the schemes agree in simulated reflectivity in below the melting layer height, but comparison to the radar observations shows that reflectivity in this area is overestimated in all schemes. Simulated $Z_{\mathrm{DR}}$ values reveal that only the FSBM scheme is able to reproduce the radar signatures reasonably well; all other schemes produce $Z_{\mathrm{DR}}$ signals within rain with too much spread. This is likely a result of the assumed exponential (Marshall-Palmer) rain PSD producing too many large and too few small droplets. The FSBM scheme on the other hand demonstrates the advantage of explicitly resolving the PSD that results in a more realistic radar signature in rain.

Above the melting layer height more deviations between the schemes are found. The P3 scheme is the only scheme not overestimating reflectivities directly above the melting layer height. All other schemes show unrealistic high reflectivities related to graupel, partly over $45 \mathrm{dBZ}$. This means that either too many or too large graupel particles are produced or that the density assumption of graupel is set too high by the Morrison, FSBM, and especially the Thompson schemes. An overestimation of reflectivities in the ice phase was found by other studies as well, which attribute this bias to wrong graupel and snow particle size distributions (e.g., Stanford et al., 2017; Varble et al., 2011). CFADs of DWR allow the simulated particle sizes to be analyzed more directly. The two Thompson schemes produce clearly confined distributions of higher occurrences of DWR in the ice phase related to snow and its growth by aggregation during sedimentation. The P3 scheme also produces distinct narrow distribution of DWR values at these heights. Nonetheless, it is wider compared to the Thompson results, caused by a mixture of unrimed, partly rimed, and unrimed particles. We believe this demonstrates the greater flexibility of the $\mathrm{P} 3$ scheme in the ice phase where this scheme deviates from the traditional hydrometeor classes and instead predicts properties for a single ice category. This seems to produce a wider range of particle characteristics (and hence DWR signals) as opposed to the other schemes, where most of the signal is produced along distinctly visible corridors. CFADs of $Z_{\mathrm{DR}}$ reveal deviations at the highest levels above $10 \mathrm{~km}$, where the Morrison and FSBM scheme produce larger values related to cloud ice that are not visible in the observed radar signal. This could either be a result of simulated cloud ice particles being too large or too many, but this could also be a result of the assumed flat cloud ice shape with an aspect ratio of 0.2. Directly above the melting layer height, three schemes (the two Thompsons and the P3) show increased $Z_{\mathrm{DR}}$ signals that are dominated by large lifted raindrops, while Morrison and FSBM do not show any increase of $Z_{\mathrm{DR}}$. The observations are between both extremes. This suggests that there are fewer large drops in the observation than simulated by Thompson-P3 or that their signals are not dominated by lifted raindrops but that other spherical particles reduce the total measured $Z_{\mathrm{DR}}$.

In general, we could demonstrate how weather simulations with varying microphysics schemes produce varying polarimetric and DWR radar signatures. However, one interesting fact is that the two Thompson schemes do not show significant differences from one another. Even though the schemes are very similar, one could have expected that the explicit prediction of droplet number concentration as well of aerosol variables would have a stronger influence on the weather simulation.

Using our framework, there are some challenges for the evaluation of the microphysics schemes performance. Using a large data set provides the possibility of a statistical evaluation. Thus, it can provide correct general overview of the schemes performance. On the other hand, considering long periods of time, multiple different weather situations produce convective cells of varying types. In our analysis, these are all analyzed together. This introduces ambiguities, 
and some individual microphysical aspects might be smeared out. A solution would be a separation of different convective cloud types, e.g., by classifying into shallow, congestus, or deep convective clouds using our $32 \mathrm{dBZ}$ echo top height (e.g., Matsui et al., 2009). Furthermore, classifications into weak/strong forcing situations could be of interest, to analyze the effect of, e.g., frontal systems on the distribution of radar signals. This will be addressed in a future application of this framework.

Furthermore, there are uncertainties connected to the radar forward simulator applied. To calculate scattering characteristics, assumptions have to be made, including the particles' aspect ratio, orientations, and shape. The variability of the simulated signals is reduced by applying fixed relations compared to the potential variability of shapes, orientations, and aspect ratios in nature. In addition, the radar forward simulator applied in our study does not consider mixed-phase particles. This means that, e.g., effects such as the bright band where particles melt cannot be reproduced by the simulations. To circumvent some ambiguities introduced this way, the comparison could be extended from radar signal space to cloud hydrometeor space; i.e., retrieved hydrometeor classes can be compared to simulated ones.

Finally, there is more noise in our radar statistics compared to the simulation statistics (for example, Fig. 5) due to the lower number of data points available from the observations. This could partially explain biases between model and radar, reminiscent of the large observational effort to statistically compare convective cloud characteristics.

The analyses shown in this work demonstrate the potential to analyze the treatment of small-scale processes within microphysics schemes. More analyses will be conducted with the methods presented, especially including dual-wavelength and polarimetric variables to analyze the simulated particle shapes and sizes. The observed radar CFADs still show large scatter due to small numbers of measurements included. More dual-wavelength data are needed to compare radar observations and a model for convective weather situations with more confidence. Another operational dual-wavelength measurement strategy is currently being established that makes use of the operational DWD volume scans and copies their strategy with the Mira-35 Ka-band radar. Because the volume scan strategy consists of multiple PPI scans of different elevations angles, the vertical resolution will be somewhat lower compared to our dual-wavelength RHI scans in strategy B. On the other hand, the PPI strategy possibly samples multiple cells at the same time, and together with the operational setup, we expect to obtain a larger number of dualwavelength measurements of convective cells.
Based on the methodology presented in this paper, more detailed analysis of some of the observed differences will be analyzed next. This will allow us to slowly approach the answer to the question of which level of complexity in microphysical processes needs to be implemented to realistically represent cloud and precipitation distribution in NWP models at the same time.

\section{Appendix A: Simulation and observation dates}

Table A1. List of convective days that were used in our analyses. Strategy A always refers to the whole day.

\begin{tabular}{ll}
\hline $\begin{array}{l}\text { Date } \\
\text { (dd-mm-yyyy) }\end{array}$ & Strategy \\
\hline $29-04-2019$ & Strategy A \\
$06-05-2019$ & Strategy A \\
$28-05-2019$ & Strategy A, strategy B (11:25-14:00 UTC) \\
$29-05-2019$ & Strategy A \\
$11-06-2019$ & Strategy A \\
$12-06-2019$ & Strategy A \\
$21-06-2019$ & Strategy A, strategy B (14:40-17:25 UTC) \\
$01-07-2019$ & Strategy A, strategy B (11:20-16:50 UTC) \\
$07-07-2019$ & Strategy A, strategy B (09:20-15:10 UTC) \\
$08-07-2019$ & Strategy A, strategy B (09:00-14:00 UTC) \\
$17-06-2020$ & Strategy A \\
$20-06-2020$ & Strategy A \\
$27-06-2020$ & Strategy A \\
$28-06-2020$ & Strategy A \\
$29-06-2020$ & Strategy A \\
$01-07-2020$ & Strategy A \\
$10-07-2020$ & Strategy A \\
$11-07-2020$ & Strategy A \\
$23-07-2020$ & Strategy A \\
$24-07-2020$ & Strategy A \\
$26-07-2020$ & Strategy A \\
$28-07-2020$ & Strategy A \\
$01-08-2020$ & Strategy A \\
$02-08-2020$ & Strategy A \\
$03-08-2020$ & Strategy A \\
$18-08-2020$ & Strategy A \\
$17-09-2020$ & Strategy A \\
$22-09-2020$ & Strategy A \\
$23-09-2020$ & Strategy A \\
$12-10-2020$ & Strategy A \\
\hline &
\end{tabular}




\section{Appendix B: Hydrometeor class CFADs}

CR-SIM calculates radar signals for the single hydrometeor classes independently, next to the total signal of all hydrometeors together. Below are CFADs of the signals calculated from the most relevant hydrometeor classes. The CFADs are shown on the original WRF grid and without attenuation correction. The FSBM simulation sometimes showed spurious rain signals on the highest levels $(>10 \mathrm{~km})$. Sometimes there are small numbers of raindrops present in the largest bins, even though the mass mixing ratio of rain is 0 in the FSBM simulation. We consider this an error with no physical meaning.

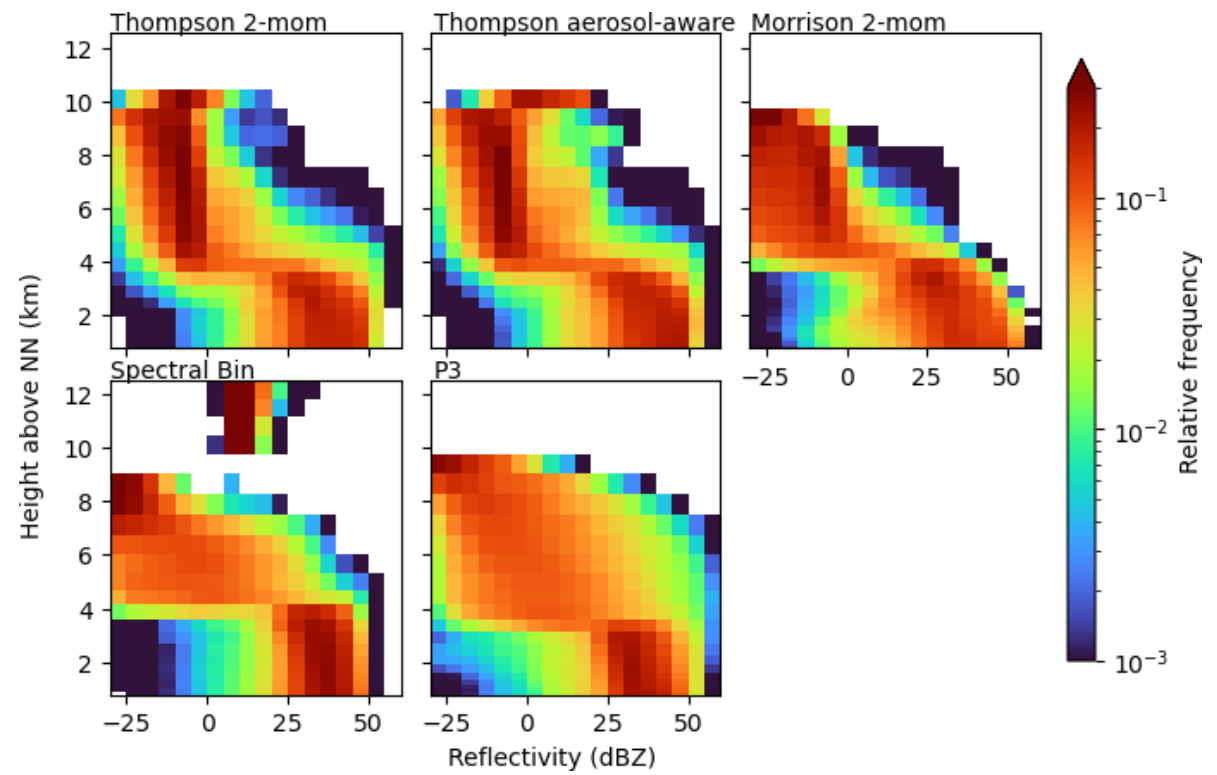

Figure B1. CFADs of simulated reflectivity of the rain hydrometeor class over 5 convective days in 2019 . 


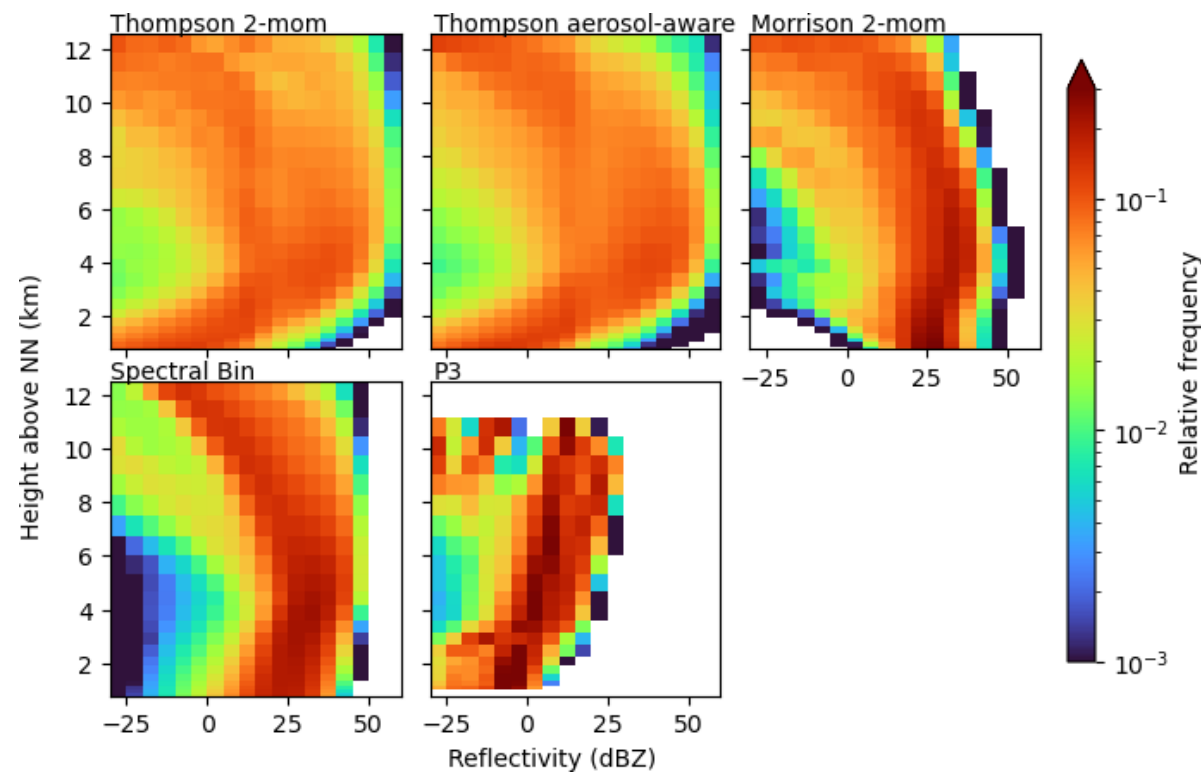

Figure B2. CFADs of simulated reflectivity of the graupel hydrometeor class over 5 convective days in 2019.

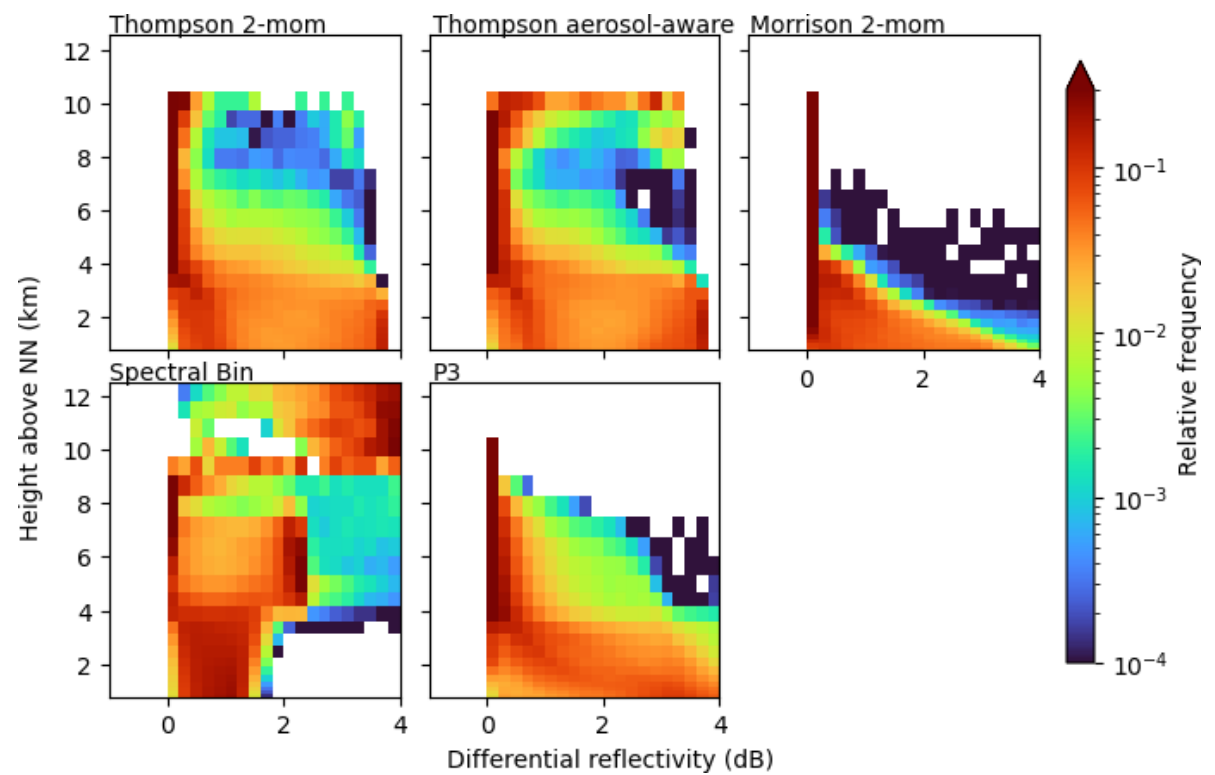

Figure B3. CFADs of simulated differential reflectivity of the rain hydrometeor class over 5 convective days in 2019 . 

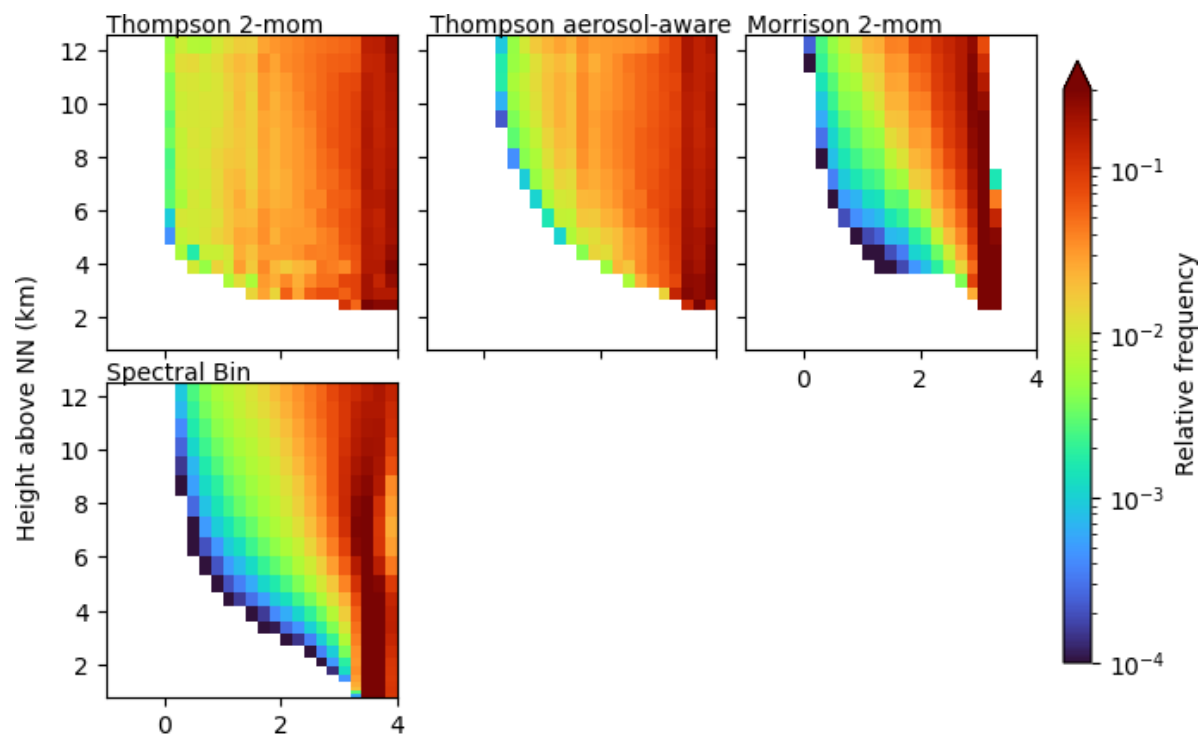

Differential reflectivity $(\mathrm{dB})$

Figure B4. CFADs of simulated differential reflectivity of the cloud ice hydrometeor class over 5 convective days in 2019 . The P3 scheme does not provide the classical cloud ice category.
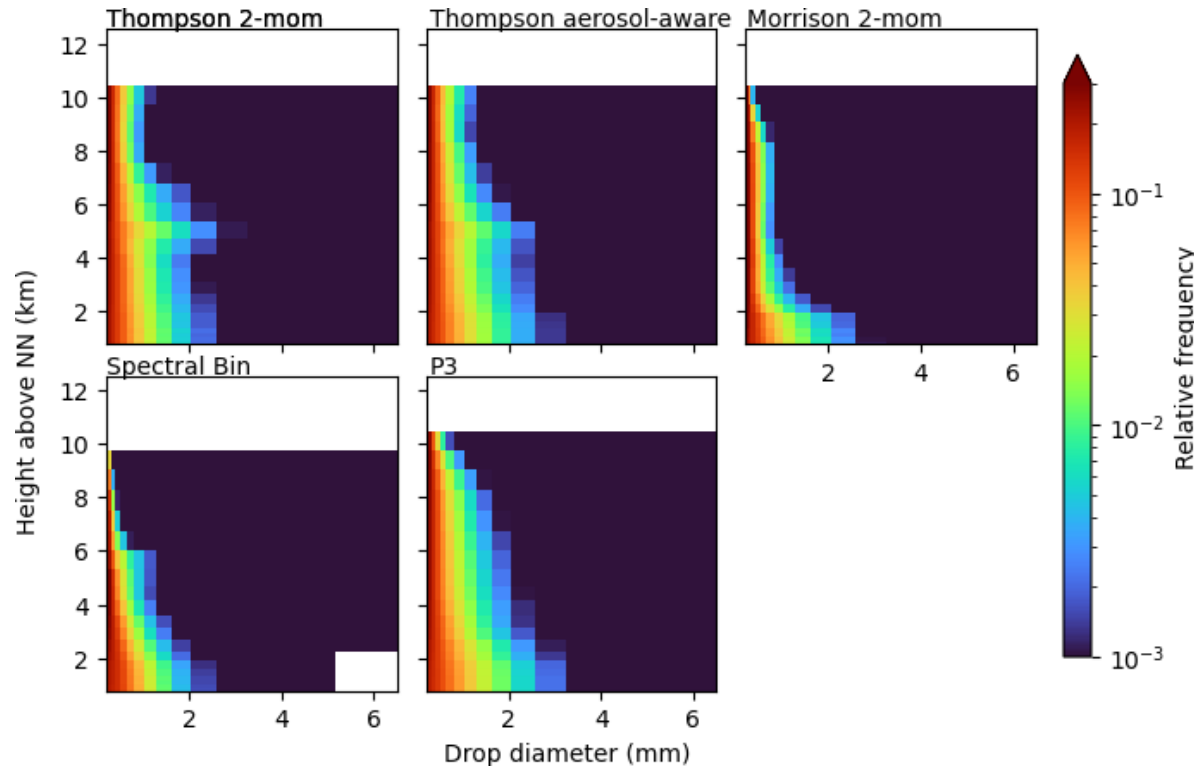

Figure B5. CFADs of simulated raindrop size distributions during the measurement periods over 5 convective days in 2019 . 
Code and data availability. The polarimetric radar data from the operational C-band radar in Isen are available for research from the German Weather Service (DWD) upon request. The Poldirad and Mira-35 data presented in this paper are available from the authors upon request. Data of WRF, CR-SIM, and TINT simulations are also available from the authors upon request. The software developed for this paper is available at https://doi.org/10.5281/zenodo.5796546 (Köcher, 2021). The Weather Research and Forecasting model (WRF; version 4.2) is publicly available on GitHub at https://github.com/wrf-model/WRF (last access: 20 June 2020; https://doi.org/10.5065/1dfh-6p97, Skamarock et al., 2019). The cell-tracking algorithm TINT is publicly available on GitHub at https://github.com/openradar/TINT (openradar, 2021). The forward operator CR-SIM (version 3.33) is available on the website of Stony Brook University (https://you. stonybrook.edu/radar/research/radar-simulators/, Oue et al., 2020).

Supplement. The supplement related to this article is available online at: https://doi.org/10.5194/amt-15-1033-2022-supplement.

Author contributions. ET, FE, MH, and GK performed radar measurements during precipitation events. GK developed the methodology presented and wrote the manuscript in its current form. TZ and CK supervised and discussed the scientific content. All authors commented on the manuscript.

Competing interests. The contact author has declared that neither they nor their co-authors have any competing interests.

Disclaimer. Publisher's note: Copernicus Publications remains neutral with regard to jurisdictional claims in published maps and institutional affiliations.

Special issue statement. This article is part of the special issue "Fusion of radar polarimetry and numerical atmospheric modelling towards an improved understanding of cloud and precipitation processes (ACP/AMT/GMD inter-journal SI)". It is not associated with a conference.

Acknowledgements. We gratefully acknowledge the project "Investigation of the initiation of convection and the evolution of precipitation using simulations and polarimetric radar observations at Cand Ka-band" (IcePolCKa; grant ZI 1132/5-1 and HA 3314/9-1) funded by the German Research Foundation (DFG) as part of the special priority program on the Fusion of Radar Polarimetry and Atmospheric Modelling (SPP-2115, PROM). Mariko Oue and Aleksandra Tatarevic were a great support for the implementation and adjustment of CR-SIM. We want to thank Fabian Hoffmann and Bernhard Mayer for their comments on the manuscript. We would also like to thank Toshi Matsui and one anonymous reviewer for their comments that improved the quality of the manuscript.
Financial support. This research has been supported by the Deutsche Forschungsgemeinschaft (grant nos. ZI 1132/5-1 and HA 3314/9-1).

Review statement. This paper was edited by Prabhakar Shrestha and reviewed by Toshi Matsui and one anonymous referee.

\section{References}

Austin, P. M. and Bemis, A. C.: A quantitative study of the "bright band" in radar precipitation echoes, J. Atmos. Sci., 7, 145-151, 1950.

Baldauf, M., Seifert, A., Förstner, J., Majewski, D., Raschendorfer, M., and Reinhardt, T.: Operational convective-scale numerical weather prediction with the COSMO model: Description and sensitivities, Mon. Weather Rev., 139, 3887-3905, 2011.

Brandes, E. A., Zhang, G., and Vivekanandan, J.: Experiments in rainfall estimation with a polarimetric radar in a subtropical environment, J. Appl. Meteorol., 41, 674-685, 2002.

Brown, P. R. and Francis, P. N.: Improved measurements of the ice water content in cirrus using a total-water probe, J. Atmos. Ocean. Tech., 12, 410-414, 1995.

Caine, S., Lane, T. P., May, P. T., Jakob, C., Siems, S. T., Manton, M. J., and Pinto, J.: Statistical assessment of tropical convectionpermitting model simulations using a cell-tracking algorithm, Mon. Weather Rev., 141, 557-581, 2013.

Cao, Q., Zhang, G., Brandes, E., Schuur, T., Ryzhkov, A., and Ikeda, K.: Analysis of video disdrometer and polarimetric radar data to characterize rain microphysics in Oklahoma, J. Appl. Meteorol. Clim., 47, 2238-2255, 2008.

Chen, F. and Dudhia, J.: Coupling an advanced land surfacehydrology model with the Penn State-NCAR MM5 modeling system. Part I: Model implementation and sensitivity, Mon. Weather Rev., 129, 569-585, 2001.

Dixon, M. and Wiener, G.: TITAN: Thunderstorm identification, tracking, analysis, and nowcasting - A radar-based methodology, J. Atmos. Ocean. Tech., 10, 785-797, 1993.

Ek, M., Mitchell, K., Lin, Y., Rogers, E., Grunmann, P., Koren, V., Gayno, G., and Tarpley, J.: Implementation of Noah land surface model advances in the National Centers for Environmental Prediction operational mesoscale Eta model, J. Geophys. Res.-Atmos., 108, 8851, https://doi.org/10.1029/2002JD003296, 2003.

Ewald, F., Groß, S., Hagen, M., Hirsch, L., Delanoë, J., and Bauer-Pfundstein, M.: Calibration of a $35 \mathrm{GHz}$ airborne cloud radar: lessons learned and intercomparisons with $94 \mathrm{GHz}$ cloud radars, Atmos. Meas. Tech., 12, 1815-1839, https://doi.org/10.5194/amt-12-1815-2019, 2019

Fan, J., Liu, Y.-C., Xu, K.-M., North, K., Collis, S., Dong, X., Zhang, G. J., Chen, Q., Kollias, P., and Ghan, S. J.: Improving representation of convective transport for scale-aware parameterization: 1. Convection and cloud properties simulated with spectral bin and bulk microphysics, J. Geophys. Res.-Atmos., 120, 3485-3509, 2015

Fan, J., Han, B., Varble, A., Morrison, H., North, K., Kollias, P., Chen, B., Dong, X., Giangrande, S. E., Khain, A., Lin, Y., Mansell, E., Milbrandt, J. A., Stenz, R., Thompson, G., and 
Wang, Y.: Cloud-resolving model intercomparison of an MC3E squall line case: Part I - Convective updrafts, J. Geophys. Res.Atmos., 122, 9351-9378, 2017.

Field, P., Hogan, R., Brown, P., Illingworth, A., Choularton, T., and Cotton, R.: Parametrization of ice-particle size distributions for mid-latitude stratiform cloud, Q. J. Roy. Meteor. Soc., 131, 1997-2017, 2005.

Flack, D. L., Gray, S. L., and Plant, R. S.: A simple ensemble approach for more robust process-based sensitivity analysis of case studies in convection-permitting models, Q. J. Roy. Meteor. Soc., 145, 3089-3101, 2019.

Fridlind, A. M., van Lier-Walqui, M., Collis, S., Giangrande, S. E., Jackson, R. C., Li, X., Matsui, T., Orville, R., Picel, M. H., Rosenfeld, D., Ryzhkov, A., Weitz, R., and Zhang, P.: Use of polarimetric radar measurements to constrain simulated convective cell evolution: a pilot study with Lagrangian tracking, Atmos. Meas. Tech., 12, 2979-3000, https://doi.org/10.5194/amt12-2979-2019, 2019.

Gallus Jr., W. A. and Pfeifer, M.: Intercomparison of simulations using 5 WRF microphysical schemes with dual-Polarization data for a German squall line, Adv. Geosci., 16, 109-116, https://doi.org/10.5194/adgeo-16-109-2008, 2008.

Grabowski, W. W.: Extracting microphysical impacts in large-eddy simulations of shallow convection, J. Atmos. Sci., 71, 44934499, 2014.

Görsdorf, U., Lehmann, V., Bauer-Pfundstein, M., Peters, G., Vavriv, D., Vinogradov, V., and Volkov, V.: A 35-GHz Polarimetric Doppler Radar for Long-Term Observations of Cloud Parameters - Description of System and Data Processing, J. Atmos. Ocean. Tech., 32, 675-690, https://doi.org/10.1175/JTECH-D14-00066.1, 2015.

Han, B., Fan, J., Varble, A., Morrison, H., Williams, C. R., Chen, B., Dong, X., Giangrande, S. E., Khain, A., Mansell, A., Milbrandt, J. A., Shpund, J., and Thompson, G.: Cloud-resolving model intercomparison of an MC3E squall line case: Part II. Stratiform precipitation properties, J. Geophys. Res.-Atmos., 124, 10901117, 2019.

Helmert, K., Tracksdorf, P., Steinert, J., Werner, M., Frech, M., Rathmann, N., Hengstebeck, T., Mott, M., Schumann, S., and Mammen, T.: DWDs new radar network and post-processing algorithm chain, in: Proc. Eighth European Conf. on Radar in Meteorology and Hydrology (ERAD 2014), Garmisch-Partenkirchen, Germany, DWD and DLR, vol. 4, 1-5 September 2014, https://www.pa.op.dlr.de/erad2014/ programme/ExtendedAbstracts/237_Helmert.pdf (last access: 16 February 2022), 2014.

Helmus, J. J. and Collis, S. M.: The Python ARM Radar Toolkit (Py-ART), a library for working with weather radar data in the Python programming language, J. Open Res. Softw., 4, e25, https://doi.org/10.5334/jors.119, 2016.

Heymsfield, A. J.: Properties of tropical and midlatitude ice cloud particle ensembles. Part II: Applications for mesoscale and climate models, J. Atmos. Sci., 60, 2592-2611, 2003.

Iacono, M. J., Delamere, J. S., Mlawer, E. J., Shephard, M. W., Clough, S. A., and Collins, W. D.: Radiative forcing by longlived greenhouse gases: Calculations with the AER radiative transfer models, J. Geophys. Res.-Atmos., 113, D13103, https://doi.org/10.1029/2008JD009944, 2008.
Jankov, I., Grasso, L. D., Sengupta, M., Neiman, P. J., Zupanski, D., Zupanski, M., Lindsey, D., Hillger, D. W., Birkenheuer, D. L., Brummer, R., and Yuan, H.: An evaluation of five ARW-WRF microphysics schemes using synthetic GOES imagery for an atmospheric river event affecting the California coast, J. Hydrometeorol., 12, 618-633, 2011.

Johnson, J., Cui, Z., Lee, L., Gosling, J., Blyth, A., and Carslaw, K.: Evaluating uncertainty in convective cloud microphysics using statistical emulation, J. Adv. Model. Earth Sy., 7, 162-187, 2015.

Jung, S.-H. and Lee, G.: Radar-based cell tracking with fuzzy logic approach, Meteorol. Appl., 22, 716-730, 2015.

Jung, Y., Xue, M., and Zhang, G.: Simulations of polarimetric radar signatures of a supercell storm using a two-moment bulk microphysics scheme, J. Appl. Meteorol. Clim., 49, 146-163, 2010.

Kessler, E.: On the Distribution and Continuity of Water Substance in Atmospheric Circulations. In: On the Distribution and Continuity of Water Substance in Atmospheric Circulations, Meteorological Monographs, vol. 10, American Meteorological Society, Boston, MA, https://doi.org/10.1007/978-1-935704-36-2_1, 1969.

Khain, A., Pokrovsky, A., Pinsky, M., Seifert, A., and Phillips, V.: Simulation of effects of atmospheric aerosols on deep turbulent convective clouds using a spectral microphysics mixed-phase cumulus cloud model. Part I: Model description and possible applications, J. Atmos. Sci., 61, 2963-2982, 2004.

Khain, A. P., Beheng, K. D., Heymsfield, A., Korolev, A., Krichak, S. O., Levin, Z., Pinsky, M., Phillips, V., Prabhakaran, T., Teller, A., van den Heever, S. C., and Yano, J.-I.: Representation of microphysical processes in cloud-resolving models: Spectral (bin) microphysics versus bulk parameterization, Rev. Geophys., 53, 247-322, 2015.

Köcher, G.: Icepolcka code, Zenodo [code], https://doi.org/10.5281/zenodo.5796546, 2021.

Kumjian, M. R.: The impact of precipitation physical processes on the polarimetric radar variables, The University of Oklahoma, 2012.

Lean, H. W., Clark, P. A., Dixon, M., Roberts, N. M., Fitch, A., Forbes, R., and Halliwell, C.: Characteristics of high-resolution versions of the Met Office Unified Model for forecasting convection over the United Kingdom, Mon. Weather Rev., 136, 34083424, 2008.

Li, X., Tao, W.-K., Khain, A. P., Simpson, J., and Johnson, D. E.: Sensitivity of a cloud-resolving model to bulk and explicit bin microphysical schemes. Part I: Comparisons, J. Atmos. Sci., 66, 3-21, 2009.

Li, Z., Zuidema, P., Zhu, P., and Morrison, H.: The sensitivity of simulated shallow cumulus convection and cold pools to microphysics, J. Atmos. Sci., 72, 3340-3355, 2015.

Martin, G., Johnson, D., and Spice, A.: The measurement and parameterization of effective radius of droplets in warm stratocumulus clouds, J. Atmos. Sci., 51, 1823-1842, 1994.

Matsui, T., Zeng, X., Tao, W.-K., Masunaga, H., Olson, W. S., and Lang, S.: Evaluation of long-term cloud-resolving model simulations using satellite radiance observations and multifrequency satellite simulators, J. Atmos. Ocean. Tech., 26, 12611274, 2009.

Maxwell Garnett, J.: Colours in metal glasses and in metallic films, Philos. T. R. Soc. Lond., 203, 385-420, 1904. 
Milbrandt, J. and Yau, M.: A multimoment bulk microphysics parameterization. Part II: A proposed three-moment closure and scheme description, J. Atmos. Sci., 62, 3065-3081, 2005.

Morrison, H. and Milbrandt, J. A.: Parameterization of cloud microphysics based on the prediction of bulk ice particle properties. Part I: Scheme description and idealized tests, J. Atmos. Sci., 72, 287-311, 2015.

Morrison, H. and Pinto, J.: Intercomparison of bulk cloud microphysics schemes in mesoscale simulations of springtime Arctic mixed-phase stratiform clouds, Mon. Weather Rev., 134, 18801900, 2006.

Morrison, H., Thompson, G., and Tatarskii, V.: Impact of cloud microphysics on the development of trailing stratiform precipitation in a simulated squall line: Comparison of one-and two-moment schemes, Mon. Weather Rev., 137, 991-1007, 2009.

Morrison, H., van Lier-Walqui, M., Fridlind, A. M., Grabowski, W. W., Harrington, J. Y., Hoose, C., Korolev, A., Kumjian, M. R., Milbrandt, J. A., Pawlowska, H., Posselt, D. J., Prat, O. P., Reimel, K. J., Shima, S. I., van Diedenhoven, B., and Xue, L.: Confronting the challenge of modeling cloud and precipitation microphysics, J. Adv. Model. Earth Sy., e2019MS001689, https://doi.org/10.1029/2019MS001689, 2020

Nakanishi, M. and Niino, H.: An improved Mellor-Yamada level-3 model: Its numerical stability and application to a regional prediction of advection fog, Bound.-Lay. Meteorol., 119, 397-407, 2006.

National Centers for Environmental Prediction/National Weather Service/NOAA/U.S. Department of Commerce: NCEP GFS 0.25 Degree Global Forecast Grids Historical Archive, Research Data Archive at the National Center for Atmospheric Research, Computational and Information Systems Laboratory [data set], https://doi.org/10.5065/D65D8PWK, 2015.

openradar: TINT, https://github.com/openradar/TINT, last access: 21 September 2021.

Oue, M., Tatarevic, A., Kollias, P., Wang, D., Yu, K., and Vogelmann, A. M.: The Cloud-resolving model Radar SIMulator (CR-SIM) Version 3.3: description and applications of a virtual observatory, Geosci. Model Dev., 13, 1975-1998, https://doi.org/10.5194/gmd-13-1975-2020, 2020 (code available at: https://you.stonybrook.edu/radar/research/ radar-simulators/, last access: 21 September 2021).

Pinto, J. O., Grim, J. A., and Steiner, M.: Assessment of the HighResolution Rapid Refresh model's ability to predict mesoscale convective systems using object-based evaluation, Weather Forecast., 30, 892-913, 2015.

Putnam, B. J., Xue, M., Jung, Y., Zhang, G., and Kong, F.: Simulation of polarimetric radar variables from 2013 CAPS spring experiment storm-scale ensemble forecasts and evaluation of microphysics schemes, Mon. Weather Rev., 145, 49-73, 2017.

Rajeevan, M., Kesarkar, A., Thampi, S. B., Rao, T. N., Radhakrishna, B., and Rajasekhar, M.: Sensitivity of WRF cloud microphysics to simulations of a severe thunderstorm event over Southeast India, Ann. Geophys., 28, 603-619, https://doi.org/10.5194/angeo-28-603-2010, 2010.

Reimann, J.: On fast, polarimetric non-reciprocal calibration and multipolarization measurements on weather radars, $\mathrm{PhD}$ thesis, Technische Universität Chemnitz, http://nbn-resolving.de/urn: nbn:de:bsz:ch1-qucosa-132088 (last access: 16 February 2022), 2013.
Ryzhkov, A., Pinsky, M., Pokrovsky, A., and Khain, A.: Polarimetric radar observation operator for a cloud model with spectral microphysics, J. Appl. Meteorol. Clim., 50, 873-894, 2011.

Schroth, A. C., Chandra, M. S., and Mesichner, P. F.: AC-band coherent polarimetric radar for propagation and cloud physics research, J. Atmos. Ocean. Technol., 5, 803-822, 1988.

Seity, Y., Brousseau, P., Malardel, S., Hello, G., Bénard, P., Bouttier, F., Lac, C., and Masson, V.: The AROME-France convectivescale operational model, Mon. Weather Rev., 139, 976-991, 2011.

Shima, S., Kusano, K., Kawano, A., Sugiyama, T., and Kawahara, S.: The super-droplet method for the numerical simulation of clouds and precipitation: A particle-based and probabilistic microphysics model coupled with a non-hydrostatic model, Q. J. Roy. Meteor. Soc., 135, 1307-1320, 2009.

Shpund, J., Khain, A., Lynn, B., Fan, J., Han, B., Ryzhkov, A., Snyder, J., Dudhia, J., and Gill, D.: Simulating a Mesoscale Convective System Using WRF With a New Spectral Bin Microphysics: 1: Hail vs Graupel, J. Geophys. Res.-Atmos., 124, 14072-14101, 2019.

Skamarock, W. C., Klemp, J. B., Dudhia, J., Gill, D. O., Liu, Z., Berner, J., Wang, W., Powers, J. G., Duda, M. G., Barker, D. M., and Huang, X.-Y.: A Description of the Advanced Research WRF Version 4, NCAR Tech. Note NCAR/TN-556+STR, 145 pp., https://doi.org/10.5065/1dfh-6p97, 2019.

Snyder, J. C., Bluestein, H. B., Dawson II, D. T., and Jung, Y.: Simulations of polarimetric, X-band radar signatures in supercells. Part I: Description of experiment and simulated $\rho$ hv rings, J. Appl. Meteorol. Clim., 56, 1977-1999, 2017.

Stanford, M. W., Varble, A., Zipser, E., Strapp, J. W., Leroy, D., Schwarzenboeck, A., Potts, R., and Protat, A.: A ubiquitous ice size bias in simulations of tropical deep convection, Atmos. Chem. Phys., 17, 9599-9621, https://doi.org/10.5194/acp17-9599-2017, 2017.

Stanford, M. W., Morrison, H., Varble, A., Berner, J., Wu, W., McFarquhar, G., and Milbrandt, J.: Sensitivity of simulated deep convection to a stochastic ice microphysics framework, J. Adv. Model. Earth Sy., 11, 3362-3389, 2019.

Stein, T. H., Hogan, R. J., Clark, P. A., Halliwell, C. E., Hanley, K. E., Lean, H. W., Nicol, J. C., and Plant, R. S.: The DYMECS project: A statistical approach for the evaluation of convective storms in high-resolution NWP models, B. Am. Meteorol. Soc., 96, 939-951, 2015.

Thompson, G. and Eidhammer, T.: A study of aerosol impacts on clouds and precipitation development in a large winter cyclone, J. Atmos. Sci., 71, 3636-3658, 2014.

Thompson, G., Field, P. R., Rasmussen, R. M., and Hall, W. D.: Explicit forecasts of winter precipitation using an improved bulk microphysics scheme. Part II: Implementation of a new snow parameterization, Mon. Weather Rev., 136, 5095-5115, 2008.

Trömel, S., Simmer, C., Blahak, U., Blanke, A., Doktorowski, S., Ewald, F., Frech, M., Gergely, M., Hagen, M., Janjic, T., Kalesse-Los, H., Kneifel, S., Knote, C., Mendrok, J., Moser, M., Köcher, G., Mühlbauer, K., Myagkov, A., Pejcic, V., Seifert, P., Shrestha, P., Teisseire, A., von Terzi, L., Tetoni, E., Vogl, T., Voigt, C., Zeng, Y., Zinner, T., and Quaas, J.: Overview: Fusion of radar polarimetry and numerical atmospheric modelling towards an improved understanding of cloud and pre- 
cipitation processes, Atmos. Chem. Phys., 21, 17291-17314, https://doi.org/10.5194/acp-21-17291-2021, 2021.

Varble, A., Fridlind, A. M., Zipser, E. J., Ackerman, A. S., Chaboureau, J.-P., Fan, J., Hill, A., McFarlane, S. A., Pinty, J.P., and Shipway, B.: Evaluation of cloud-resolving model intercomparison simulations using TWP-ICE observations: Precipitation and cloud structure, J. Geophys. Res.-Atmos., 116, D12206, https://doi.org/10.1029/2010JD015180, 2011.

Varble, A., Zipser, E. J., Fridlind, A. M., Zhu, P., Ackerman, A. S., Chaboureau, J.-P., Collis, S., Fan, J., Hill, A., and Shipway, B.: Evaluation of cloud-resolving and limited area model intercomparison simulations using TWP-ICE observations: 1. Deep convective updraft properties, J. Geophys. Res.-Atmos., 119, 13891, 2014.

White, B., Gryspeerdt, E., Stier, P., Morrison, H., Thompson, G., and Kipling, Z.: Uncertainty from the choice of microphysics scheme in convection-permitting models significantly exceeds aerosol effects, Atmos. Chem. Phys., 17, 12145-12175, https://doi.org/10.5194/acp-17-12145-2017, 2017.
Xue, L., Fan, J., Lebo, Z. J., Wu, W., Morrison, H., Grabowski, W. W., Chu, X., Geresdi, I., North, K., Stenz, R., Gao, Y., Lou, X., Bansemer, A., Heymsfield, A. J., McFarquhar, G. M., and Rasmussen, R. M.: Idealized simulations of a squall line from the MC3E field campaign applying three bin microphysics schemes: Dynamic and thermodynamic structure, Mon. Weather Rev., 145, 4789-4812, 2017.

Yuter, S. E. and Houze Jr, R. A.: Three-dimensional kinematic and microphysical evolution of Florida cumulonimbus. Part II: Frequency distributions of vertical velocity, reflectivity, and differential reflectivity, Mon. Weather Rev., 123, 1941-1963, 1995. 